\title{
Organoid technology in female reproductive biomedicine
}

\author{
Heidar Heidari-Khoei ${ }^{1 \dagger}$, Fereshteh Esfandiari ${ }^{1 \dagger}$, Mohammad Amin Hajari ${ }^{1}$, Zeynab Ghorbaninejad', \\ Abbas Piryaei ${ }^{2,3^{*}}$ and Hossein Baharvand ${ }^{1,4^{*}}$ (i)
}

\begin{abstract}
Recent developments in organoid technology are revolutionizing our knowledge about the biology, physiology, and function of various organs. Female reproductive biology and medicine also benefit from this technology. Organoids recapitulate features of different reproductive organs including the uterus, fallopian tubes, and ovaries, as well as trophoblasts. The genetic stability of organoids and long-lasting commitment to their tissue of origin during long-term culture makes them attractive substitutes for animal and in vitro models. Despite current limitations, organoids offer a promising platform to address fundamental questions regarding the reproductive system's physiology and pathology. They provide a human source to harness stem cells for regenerative medicine, heal damaged epithelia in specific diseases, and study biological processes in healthy and pathological conditions. The combination of male and female reproductive organoids with other technologies, such as microfluidics technology, would enable scientists to create a multi-organoid-on-a-chip platform for the next step to human-on-a-chip platforms for clinical applications, drug discovery, and toxicology studies. The present review discusses recent advances in producing organoid models of reproductive organs and highlights their applications, as well as technical challenges and future directions.
\end{abstract}

Keywords: Organoids, Reproductive organs, Reproductive medicine, Organoid-on-a-chip

\section{Background}

The female reproductive system is of utmost importance to a woman's quality of life; it produces sex hormones and oocytes, provides the site for fertilization, and supports the fetal development $[1,2]$. Diseases and disorders of the female reproductive system are not adequately studied, especially in the areas of endometriosis, gynecological cancers, sexually transmitted diseases (STDs), and pregnancy disorders (including intrauterine growth restriction,

\footnotetext{
* Correspondence: piryae@sbmu.ac.ir; Baharvand@royaninstitute.org ${ }^{\dagger}$ Heidar Heidari-Khoei and Fereshteh Esfandiari contributed equally to this work.

${ }^{2}$ Urogenital Stem Cell Research Center, Shahid Beheshti University of Medical Sciences, Tehran, Iran

'Department of Stem Cells and Developmental Biology, Cell Science Research Center, Royan Institute for Stem Cell Biology and Technology, ACECR, P.O. Box: 16635-148, Tehran 1665659911, Iran

Full list of author information is available at the end of the article
}

miscarriage, and recurrent miscarriage), in addition to medications that have deleterious effects on the reproductive system [2-5]. Limited access to reproductive material, especially those for maternal-embryo interactions, and unavailable reliable experimental models are serious challenges for studies in this field [6].

Conventional in vitro systems that include twodimensional (2D) and three-dimensional (3D) cell cultures have serious pitfalls that make them unsuitable for studying the female reproductive system. The 2D culture of immortalized cell lines or those derived from tumors in reproductive organs have led to numerous insights about the biology and physiology of the reproductive system; their advantages include reproducibility and ease of access. However, they lack many complex features of in vivo microenvironments, including a cell-cell/cell-extracellular matrix (ECM), the display of a relatively homogenous phenotype, and are not

(c) The Author(s). 2020 Open Access This article is licensed under a Creative Commons Attribution 4.0 International License, which permits use, sharing, adaptation, distribution and reproduction in any medium or format, as long as you give appropriate credit to the original author(s) and the source, provide a link to the Creative Commons licence, and indicate if changes were made. The images or other third party material in this article are included in the article's Creative Commons licence, unless indicated otherwise in a credit line to the material. If material is not included in the article's Creative Commons licence and your intended use is not permitted by statutory regulation or exceeds the permitted use, you will need to obtain permission directly from the copyright holder. To view a copy of this licence, visit http://creativecommons.org/licenses/by/4.0/ The Creative Commons Public Domain Dedication waiver (http://creativecommons.org/publicdomain/zero/1.0/) applies to the data made available in this article, unless otherwise stated in a credit line to the data. 
representative of in vivo cellular diversity. Because of genetic alterations in cell lines, they fail to recapitulate key features of native tissues as well as different active cell signaling pathways and function from those in the native cells [7]. Moreover, rapid loss of phenotype and tissuerelated functions occur following $2 \mathrm{D}$ culture of primary cells [8]. Therefore, 2D culture systems do not adequately show the natural 3D environment of cells; in turn, they fail to mimic in vivo cellular functions and signaling pathways, and may provide misleading and non-predictive data for in vivo responses. The $3 \mathrm{D}$ cell aggregates exhibit improved function, but lack cellular polarity and the 3D organization that is present in vivo. Other 3D culture systems include spheroids that often lack the capacity for self-renewal and differentiation due to the absence of relevant progenitor or stem cells $[9,10]$. The organ explant or organotypic slice cultures that recapitulate the complex 3D architecture, cellular heterogeneity, and function of the native organ are very useful for the study of development and physiology, but they are limited by their inability to proliferate, their short-term nature, and cell phenotype drift due to improper orientation in culture media $[11,12]$.

The recently developed organoid technology provides new in vitro models to serve as both tissue and organ proxies to bridge the gap between in vitro and in vivo [13]. Organoids are self-organizing structures that recapitulate a numerous of biological and pathological features of organs such as spatially restricted lineage commitment, specific functions of the organ, multiple organ-specific cell types, and cell-cell and cell-matrix interactions. They represent genetic stability and maintain commitment to their tissue of origin during the long-term culture that allows for access to an unlimited source of material to support research in this field. Moreover, they can serve as substitutes for animal and in vitro models and provide the opportunity for high throughput studies, personalized medicine, drug and toxicity testing, disease modeling, and present a promising way for autologous transplantation. Organoids recapitulate features of different reproductive organs. In this regard, the uterus, fallopian tubes, and ovaries as well as trophoblast organoids have been created in the laboratory. In this review, we will discuss recent advances in producing organoid models of reproductive organs and highlight their applications, in addition to discussing technical challenges and future directions.

\section{Main text}

\section{Ovarian organoids}

Ovarian cancer represents the fifth leading cause of cancer deaths in women in the US [14]. Access to reliable experimental models that address clinical challenges, such as early detection, tumor recurrence, and acquired chemotherapy resistance, is a high priority in ovarian cancer research. Recently, successful generation ovarian cancer organoids was reported by two separate groups $[15,16]$. These organoids recapitulate histological and genomic features of the lesions from which they were derived and represent intra- and interpatient heterogeneity $[15,16]$. Moreover, ovarian cancer organoids display somatic mutations and amplifications/deletions [15] and recapitulated the parent tumor's marker expression and mutational landscape [16]. Moreover, the organoids showed tumor-specific sensitivity to chemotherapeutic drugs and therefore provide a reliable preclinical tools for drug screening and discovery [15, 16]. Moreover, xenografting these organoids can provide an in vivo platform for drug screening [15]. Maru et al. have previously reported that ovarian organoids recapitulated mutation profile and intra-tumor heterogeneity [17].

Developing organoids from other ovarian disorders such as premature ovarian failure and polycystic ovary would provide a platform to study the mechanisms that underlie these diseases and enable the development of new drugs and treatments.

\section{Fallopian tube organoids}

The fallopian tube (oviduct or uterine tube) is a central organ of the female reproductive system that plays an essential role in oocyte maturation and selection, gamete and embryo transportation, sperm reservoir, control of polyspermy, fertilization and early embryonic development [18]. It is believed that the fallopian tube is the origin site of several clinically important diseases such as high-grade serous ovarian cancer (the deadliest form of gynecological cancer), pelvic inflammatory disease (PID), and infertility $[19,20]$. Direct examination and study of fallopian tubes in alive patients is extremely difficult and somehow impossible due to its intra-abdominal location and structure. Therefore, an in vitro organoid model that recapitulates the in vivo structure and function of fallopian tubes is advantageous for supporting studies in this field.

There are two main methods for fallopian tube organoids, the air-liquid interphase (ALI) system and self-organizing organoids. Chen et al. have applied an ALI system for longterm culture of murine, porcine, and bovine (three common species used in reproductive biology) oviductal epithelial cells (OEC). Isolated OEC have been cultured within an insert submerged in a proliferation-inducing medium for 7 days to form a confluent layer, and then the medium was aspirated from apical compartment to establish an air-liquid interface that supported polarization and differentiation. Subsequently, during the differentiation period, the cells were grown in serum-free or serum-reduced media from the basolateral compartment for two or 3 weeks. During this period, the cells developed from a flat layer to a columnarshaped layer that consisted of ciliated and secretory cells. The polarized structure was maintained for at least 6 weeks. 
After the differentiation period, the cells secreted an oviduct fluid surrogate that could support embryonic development up to the blastocyst stage without the addition of embryo culture medium [21]. Despite the polarized structure and in vivo-like function, this culture system differs from the current organoid concept. This culture system lacks the tubular folded architecture and inserts, and does not permit live imaging or perfusion studies that limits its use to study gamete interactions and early embryo development in detail $[8,21]$. In self-organizing organoids, the fallopian tube was generated based on the modified intestinal organoid protocol. Isolated fallopian epithelial cells were seeded in a 2D culture, followed by culture in 3D Matrigel matrix supplemented with growth factors (epidermal growth factor [EGF], fibroblast growth factor [FGF], and TGF- $\beta$ ), niche specific factors (Wnt3a, R-spondin-1 [RSPO1], ALK4/5, and Noggin), and an inhibitor of anoikis (ROCK inhibitor) (Fig. 1, Table 1) [25]. In contrast to other organoid models, this study showed that the addition of Wnt3a and RSPO1 maintained the stem cell subpopulations for an extended period of time and also allowed full differentiation. The presence of EGF doubled the number of organoids, addition of RSPO1 increased their size, and addition of ALK4/5 was crucial for quasi-indefinite expansion (Table 2). Monoclonal cystic organoids that contained ciliated and secretory cells have been successfully generated from a single EpCAM+ cell. Fallopian tube organoids faithfully recapitulate the structure of native tissue, show highly polarized columnar cells, fully developed inter-cellar junctions, fully assembled cilia, active secretion, and an orientation of the apical pole to the luminal side. These organoids are responsive to hormonal stimulation, show robust growth and can be maintained long-term in culture. Successful generation of monoclonal organoids from different donors has confirmed the presence of stem cells in the generated organoids, as well as fallopian tube epithelium (FTE).

Scientists reported a human iPSC reprogramming method for generating FTE organoids. In this study, different WNT and BMP signaling were modulated to successful direct differentiation of human pluripotent stem cells into Müllerian cells and subsequent proMüllerian growth factors were used to develop FTE precursors. Then, FTE precursors were cultured in Matrigel with phenol red where they formed an organoid structure. However, when cultured in Matrigel without phenol red, they became branched and formed an unorganized matrix [22]. Phenol red is widely used in cell culture as a pH indicator; it bears structural similarity to nonsteroidal estrogens, exhibits estrogen-like bioactivity, and promotes proliferation in estrogen-sensitive cells such as fallopian tube cells $[29,30]$. Therefore, their results have shown that estrogen effects FTE differentiation and maturation [22]. Human iPSC-derived FTE organoids were grown in 3D Matrigel with estrogen and progesterone supplemented media for an extended period. Immunocytochemistry results showed that FTE organoids formed secretory (PAX8+) and ciliated (TUBB4A+) cells. Expression of a mature epithelial cell marker (CDH1) in the organoid was comparable to fresh human fallopian tube tissue. In addition, the proper differentiation of iPSC-derived organoids into fallopian tube cells was confirmed using heat map analysis [22].

The described fallopian tube organoid models closely mimic normal physiology and architecture of the human FTE. Therefore, they provide promising models to study the biology and pathology of fallopian tubes with regards to screening technologies, cancer biology, and reproductive medicine [25]. However, this system has limitations for gamete or embryo interaction studies due to its small size and inaccessible luminal compartment that require labor-intensive approaches, such as microinjection.

\section{Endometrial organoids}

The human endometrium is a dynamic tissue that undergoes cyclic changes in response to steroid hormones as well as paracrine and autocrine factors to be prepared for embryo implantation. Embryo implantation is a highly complex process that requires a receptive endometrium, a competent blastocyst, and a synchronized maternal-embryo dialogue [31]. The endometrium is also involved in many gynecologic conditions, including infertility, dysmenorrhea, endometrial polyps, endometriosis, and endometrial cancer which is the most common cancer of the female reproductive organs [32].

For first time, Bläuer et al. developed and validated a culture condition in which normal human endometrium was cultivated as glandular organoids within Matrigel matrix in co-culture with stromal cells. However, this $3 \mathrm{D}$ culture system differed in principle and protocols from the currently adopted organoid concept [33]. Successful generation of endometrial organoids was reported by two separate groups in 2017 for mouse and human endometria [3, 4]. These endometrial organoids were established by embedded dissociated endometrial cells in Matrigel droplets in culture medium (Fig. 1 and Table 2) that are commonly used to support the development organoid models of other organs. The endometrial organoids recapitulated the molecular and functional characteristics of their cells of origin. Endometrial organoids, like in vivo endometrium, exhibit glandular-type selforganization, apicobasal polarity, and functional behavior such as mucus production, and are responsive to sex hormones [3, 4]. Endometrial organoids have been derived from endometrial adenocarcinomas and the normal adjacent endometrium from post-menopausal women [3]. Unlike healthy endometrial-derived organoids, the tumorderived organoids presented with a range of patient-specific morphologies, including pleomorphic cells with hyperchromatic nuclei, disorganized epithelium, basement membrane 


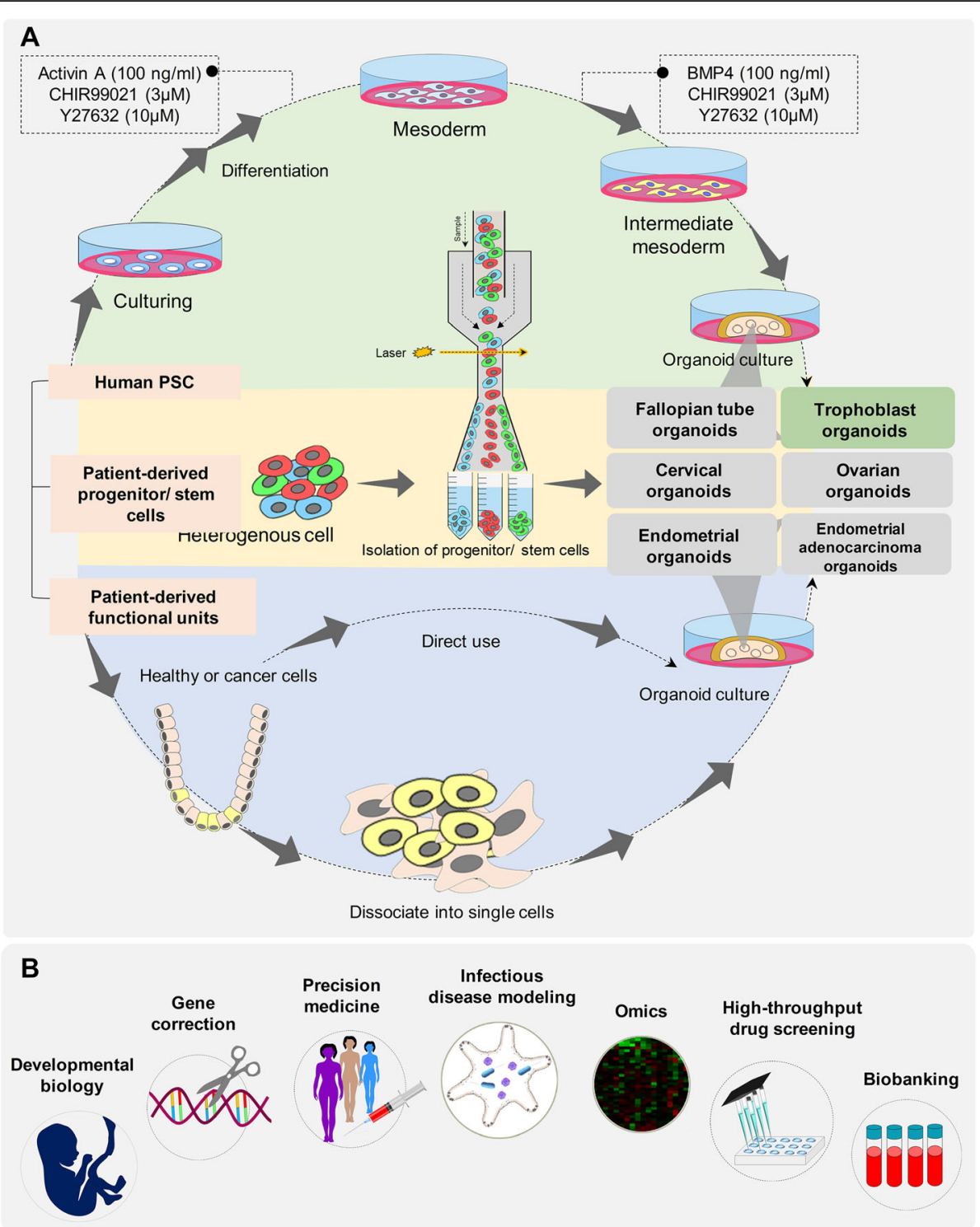

Fig. 1 Schematics of mainstream human reproductive organoids and their applications. Different reproductive organoid development processes. Human reproductive organoids can be generated from normal or malignant primary tissues. Alternatively, somatic cells can be reprogrammed to become induced pluripotent stem cells, which are used as sources of reproductive organoids through directed differentiation. Primary tissues are dissociated into functional units that contain adult stem cells. These functional units can be digested into single cells and sorted to enrich stem cells for an organoid culture. Furthermore, iPSCs undergo directed differentiation towards the desired germ lineage and are subsequently embedded in matrix such as Matrigel to initiate an organoid culture. Organoids are typically cultured in an extracellular matrix (ECM) surrounded by culture media supplemented with specific niche factors. Applications of reproductive organoids. In basic research, organoid technologies provide new insights to understand the principles of development, homeostasis, and regeneration. Moreover, targeted gene therapy using the CRISPR/Cas9 system can be used on organoids derived from disease tissue. In personalized medicine, patient-derived organoids (PDO) can help to identify the best drug for each patient and diseases, including endometrial and ovarian cancers. Omics analysis (transcriptomics, proteomics, epigenomics, and metabolomics) of healthy and diseased organoids can reveal the molecular mechanisms involved in tissue differentiation and diseases. Bio-banked organoids can be used to identify drugs that are effective against a broad spectrum of disease phenotypes. Organoids also represent useful tools for the study of infectious diseases because they replicate the complexity of the in vivo system yet still retain the accessibility of an in vitro system

breaching and invasion of isolated cells into the surrounding Matrigel. However, the tumor derivedorganoids were positive for glandular markers MUC1 and SOX17, which confirmed their glandular origin. Investigation of chromosomal stability of endometrial organoids using a comparative genomic hybridization (CGH) array demonstrated that the established organoids preserved their genetic integrity over several months in culture. These genetically stable endometrial organoids could be expanded and frozen without 
Table 1 Frequently used growth media constituents, their working mechanisms, effects and applications

\begin{tabular}{|c|c|c|c|}
\hline & & Mechanism of action & Function \\
\hline \multirow[t]{2}{*}{$\begin{array}{l}\text { Frequently used } \\
\text { factors }\end{array}$} & Noggin & $\begin{array}{l}\text { Binds and inactivates members } \\
\text { of the TGF- } \beta \text { superfamily } \\
\text { signaling proteins, such as BMP4. }\end{array}$ & $\begin{array}{l}\text { Allows for long-term } \\
\text { expansion of organoids } \\
\text { by preventing } \\
\text { differentiation. }\end{array}$ \\
\hline & RSPO1 & $\begin{array}{l}\text { Interacts with WNT4 in the } \\
\text { process of female sex } \\
\text { development. } \\
\text { Potentiates the cellular response } \\
\text { to Wnts. }\end{array}$ & $\begin{array}{l}\text { Facilitates the growth, } \\
\text { expansion, and } \\
\text { long-term culture of } \\
\text { organoids. } \\
\text { Plays a crucial role in } \\
\text { formation and stem cell } \\
\text { maintenance of FTO. }\end{array}$ \\
\hline
\end{tabular}

Significance in reproductive

WNT3A The ligand of the canonical Wnt signaling pathway, Interacts with the LRP6/Frizzled receptor complex

HGF

Activates a tyrosine kinase signaling cascade after binding to the proto-oncogene c-Met receptor

EGF

Activates the RAS/RAF/MEK/ERK signaling pathway

FGF10

Acts mostly on the epithelium via Fgfr2b.

Prostaglandin $E_{2} \quad$ Binding and activation of the prostaglandin E2 receptor.

Nicotinamide A form of vitamin B3.

Molecule

Y27632

inhibitors
Crucial for maintenance of stable growth over time.

Epithelial-cell mitogen.

Epithelial-cell mitogen. Crucial for maintenance of stable growth over time.

Supports proliferation and differentiation of FTE cells.

Epithelial-cell mitogens.

Critical for maintenance of CTB-orgs.

Withdrawal of nicotinamide had the strongest effect on the numbers of EMO that formed.

Important for long-term culture and passaging of organoids.

Maintains epithelial-cell features growth, expansion and passageability of mouse EMO.

The presence of WNT3A (alone or together with RSPO1) enhanced the WNT3A was not needed for further expansion and passaging of human EMO.

numbers and/or sm reduced growth, expansion, and passageability of mouse EMO. expansion of CTB-orgs.

The lack of A-83-01 resulted in reduced numbers and/or smaller human EMO.
Inhibits anoikis of dissociated cells.

Alk3/4/5 inhibitor. Blocks the TGF- $\beta$ pathway. organoid cultures

The lack of Noggin resulted in reduced numbers and/or smaller human EMO.

The lack of Noggin growth markedly reduced the expansion and passageability of mouse EMO. Limited differentiation and promoted trophoblast survival in CTB-orgs.

The lack of RSPO1 resulted in reduced numbers and/or smaller human EMO. Removal of RSPO1 alone did not affect mouse EMO formation efficiency.

The lack of RSPO1 markedly reduced growth, expansion and passageability of mouse EMO.

RSPO1 was required for efficient, long-term human EMO expansion. In the absence of RSPO1, human organoids could no longer be passaged after $\mathrm{P} 3$.

Addition of RSPO1 increased the

FTO size.

RSPO1 is not absolutely required for long-term maintenance of mouse FTE organoids.

Addition of RSPO1 increased

differentiation of FTE organoids toward the ciliated lineage.

Withdrawal of RSPO1 promoted

trophoblast outgrowth from the outer CTB layers and expression of HLA-G at distal sites from the CTB-orgs.

Critical for maintenance of CTB-orgs.

Ref

$[4,5,22,23]$ Critical for maintenance of CTB-ORGs. Required for long-term expansion of CTB-orgs. 
Table 1 Frequently used growth media constituents, their working mechanisms, effects and applications (Continued)

\begin{tabular}{|c|c|c|c|c|}
\hline & Mechanism of action & Function & $\begin{array}{l}\text { Significance in reproductive } \\
\text { organoid cultures }\end{array}$ & Ref \\
\hline SB202190 & p38 inhibitor. & & $\begin{array}{l}\text { Decreasing concentrations of p38i were } \\
\text { beneficial for long-term expansion of } \\
\text { endometrial cancer organoids. }\end{array}$ & [24] \\
\hline SB431542 & TGF- $\beta$ R kinase inhibitor IV. & $\begin{array}{l}\text { Crucial for quasi-indefinite } \\
\text { expansion of FTO. }\end{array}$ & $\begin{array}{l}\text { Without TGF- } \beta \text {, RK inhibitor FTO had } \\
\text { slower expansion and finally growth } \\
\text { arrest by four to six passages (three to } \\
\text { four months). } \\
\text { Important for formation and } \\
\text { maintenance of large FTE organoids. }\end{array}$ & {$[23,25]$} \\
\hline CHIR99021 & Inhibitor of GSK3. & & Critical for maintenance of CTB-orgs. & [5] \\
\hline
\end{tabular}

EMO Endometrial organoid, FTO Fallopian tube organoid, CTO Cytotrophoblast, BMP4 Bone morphogenetic protein-4, RSPO1 R-spondin-1, Fgfr2b Fibroblast growth factor receptor $2 \mathrm{~b}$, FTE Fallopian tube epithelium, HGF Hepatocyte growth factor

loss of their proliferative ability after thawing to create a patient-specific biobank of endometrial tissues [3]. This culture system has the ability to expand the small quantity of starting material for a variety of high throughput assessments and could be a valuable platform for investigating implantation problems, the histotrophic nutrition period in early pregnancy, novel therapeutic strategies for gynecologic pathologies such as endometriosis and endometrial cancer, and generate an endometrial biobank. However, the current organoids lack stromal cells. It is well known that reciprocal interaction between endometrial epithelial and stromal cells is responsible for physiological functions (proliferation, differentiation, and decidualization) and emergence of several pathologic conditions such as endometrial carcinoma [34-36]. Without a more complete complement of cell types, endometrial organoids will always lack the context they need to be actual miniorgans. Recently, a co-culture of intestinal organoids with stromal cells was developed by Stzepourginski et al. [37]. Co-culture of the present endometrial organoids with stromal cells could further complement the organoid model and provide a relevant model to study reciprocal epithelium stroma interactions that occur in vivo [36]. The inaccessible luminal compartment and apical aspect of the epithelium of organoids present a number of challenges to physiologically relevant studies [38]. Unfolding the spherical organoid into a 2D planar tissue construct and monolayer culture of primary epithelial cells from organoids would provide an accessible luminal compartment for related studies, such as embryo cultures [38].

\section{Trophoblast organoids}

The placenta is an extraembryonic organ that is essential for survival and development of the mammalian embryo. During implantation in humans, the trophectoderm layer of the blastocyst attaches to the endometrial epithelium and continues to differentiate into trophoblast subtypes: the cytotrophoblast (CTB), extravillous CTB (EVT), and syncytiotrophoblast (STB). Undifferentiated
CTB cells grow through the STB to form cell columns and chorionic villi. The CTB cells at the tips of villi differentiate into EVT, which invade the deciduum. EVTs have two cell types: interstitial EVT cells that invade the decidualized endometrium and endovascular EVTs that invade and remodel the spiral arteries [39, 40]. Multinucleated STB cells are responsible for nutrient exchange and synthesis. They secrete placental hormones such as placental lactogen, chorionic gonadotropin, and progesterone in addition to numerous other proteins and steroids to maintain pregnancy. These cells are formed by fusion of interstitial CTB cells [41]. Placental dysfunction and insufficiency results in major pregnancy-related disorders such as intrauterine growth restriction, preeclampsia, miscarriage, recurrent abortion, and preterm labor $[42,43]$. Our current knowledge about the human placenta is limited due to the lack of representative functional models [44]. Several experimental models, including animal models and in vitro cell culture models, have been used to study the placenta. However, distinct structural and functional differences exist between human and other animal placentas; thus, data from animal models is not relevant to humans $[45,46]$. In vitro models of human trophoblasts include placenta-derived cell lines, isolated primary placenta cells, and human placenta tissue explants. Several cell lines have been established from choriocarcinoma cells: JEG-3, BeWo, and JAR. Advantages of these cell lines include ease of use; unlimited supply of material; more pure cell source; less expensive to procure; ease of use for gene silencing approaches; and these sources bypass some of the ethical concerns associated with the use of animal or primary human tissues [47]. However, immortal cell lines have several drawbacks due to their malignant transformations. This problem may be overcome by using immortalized primary trophoblast cells, such as the HTR-8/ SVneo cell line derived by transfecting first trimester EVT cells with the gene that encodes for simian virus 40 large $\mathrm{T}$ antigen, or $\mathrm{ACH}-3 \mathrm{P}$ and AC1-M59 cell lines, which are choriocarcinoma cells fused with primary first 
Table 2 Summary of sources and culture conditions used in the development of various reproductive organoids

\begin{tabular}{|c|c|c|c|c|c|c|}
\hline Organoids & Source & Culture conditions & Cell types in organoids & Matrix & $\begin{array}{l}\text { Generation } \\
\text { efficiency }\end{array}$ & Reference \\
\hline $\begin{array}{l}\text { Ovarian } \\
\text { cancer }\end{array}$ & Ovarian cancer tissue & $\begin{array}{l}\text { Establishment: Advanced DMEM/F12, } \\
\text { Glutamax, HEPES, Noggin, Rspo1, } \\
\text { WNT3A, B27, FGF10, bFGF, nicotinamide, } \\
\text { N-acetyl-L-cysteine, A83-01, } \\
\text { Heregulin } \beta-1 \text {, hEGF, IGF-1, HGF, } \\
\text { Forskolin, Hydrocortisone, NRG1, p38i } \\
\text { (SB203580), } \beta \text {-Estradiol, Y-27632 } \\
\text { Test components: } \\
\text { carboplatin, paclitaxel, alpelisib, pictilisib, } \\
\text { MK2206, AZD8055, Niraparib, adavosertib, } \\
\text { gemcitabine, doxorubicin, nutlin-3 }\end{array}$ & $\begin{array}{l}\text { Disease and original } \\
\text { tumor phenotype }\end{array}$ & $\begin{array}{l}\text { Cultrex } \\
\text { growth factor } \\
\text { reduced BME } \\
\text { type } 2\end{array}$ & $33-65 \%$ & {$[15,16]$} \\
\hline \multirow[t]{3}{*}{$\begin{array}{l}\text { Fallopian } \\
\text { tube }\end{array}$} & $\begin{array}{l}\text { human iPSC lines (87iCTR- } \\
\text { n3, 01iMEC-n4, 14iCTR-n6) }\end{array}$ & $\begin{array}{l}\text { Mesoderm induction: Activin A, } \\
\text { CHIR99021, Y27632 } \\
\text { Intermediate mesoderm induction: } \\
\text { BMP4, CHIR99021, Y27632 } \\
\text { The fallopian tube epithelial cells } \\
\text { differentiation: WNT4, Follistatin } \\
\text { Establishment: } \\
\text { DMEM/F12, reconstituted Ultroser, } \\
\text { Y-27632, estrogen, progesterone, } \\
\text { conditioned media from FTE cells } \\
\text { Maturation: cultured in 3D Matrigel for } \\
\text { an extended period with estrogen and } \\
\text { progesterone supplemented media }\end{array}$ & $\begin{array}{l}\text { Ciliated (TUBB4A and } \\
\text { FOXJ1) cells } \\
\text { secretory (PAX8) cells }\end{array}$ & Matrigel & NR & [22] \\
\hline & Lin - EPCAM+ FTE cells & $\begin{array}{l}\text { Establishment: Advanced DMEM/F12, } \\
\text { GlutaMAX, B27, EGF, TGFBR1 Kinase } \\
\text { Inhibitor IV, Y-27632 } \\
\text { Differentiation: RSPO1 }\end{array}$ & $\begin{array}{l}\text { PAX8+ secretory cells } \\
\text { acetylated tubulin } \\
\text { (AcTUB) + ciliated cells }\end{array}$ & Matrigel & NR & [23] \\
\hline & $\begin{array}{l}\text { Epithelial progenitor } \\
(\text { EpCAM+) cell }\end{array}$ & $\begin{array}{l}\text { Establishment: Advanced DMEM/F12, } \\
\text { conditioned human Wnt3A medium, } \\
\text { conditioned human RSPO1 medium, } \\
\text { GlutaMAX, B27, N2, human EGF, human } \\
\text { noggin, human FGF10, nicotinamide, } \\
\text { Y-27632, TGF- } \beta \text { R Kinase Inhibitor IV } \\
\text { hormonal stimulation: beta-oestradiol, } \\
\text { progesterone }\end{array}$ & $\begin{array}{l}\text { Pax8-positive secretory } \\
\text { cells } \\
\text { Pax8 negative, acetylated } \\
\text { tubulin-positive ciliated } \\
\text { cells }\end{array}$ & Matrigel & NR & [25] \\
\hline \multirow[t]{4}{*}{ Endometrium } & $\begin{array}{l}\text { the mouse endometrial } \\
\text { glandular-type fragments }\end{array}$ & $\begin{array}{l}\text { Establishment: DMEM/F12, GlutaMAX, } \\
\text { B27, ITS, FGF10, nicotinamide, WNT3A; } \\
\text { R-spondin 1, Noggin, A83-01 } \\
\text { Hormonal stimulation: beta-oestradiol, } \\
\text { progesterone }\end{array}$ & $\begin{array}{l}\text { secretory cells } \\
\text { ciliated cells }\end{array}$ & Matrigel & NR & [4] \\
\hline & $\begin{array}{l}\text { the human endometrial } \\
\text { glandular-type fragments }\end{array}$ & $\begin{array}{l}\text { Establishment: WNT3A; R-spondin 1, } \\
\text { EGF, FGF10, Noggin, A83-01, ITS, } \\
\text { N-acetyl-L-cysteine, p38 inhibitor } \\
\text { SB202190Hormonal stimulation: } \\
\text { beta-oestradiol, progesterone }\end{array}$ & $\begin{array}{l}\text { secretory cells } \\
\text { ciliated cells }\end{array}$ & Matrigel & NR & [4] \\
\hline & $\begin{array}{l}\text { Dissociated endometrial } \\
\text { cancer cells }\end{array}$ & $\begin{array}{l}\text { Establishment: DMEM/F12, B27, } \\
\text { Glutamax, N-acetyl cysteine, Primocin, } \\
\text { nicotinamide, A 83-01, SB 202190, } \\
\text { Y- 27632, 17-A estradiol } \\
\text { Test components: } \\
\text { Megestrol acetate, fulvestrant, letrozole, } \\
\text { mifepristone, erlotinib, linsitinib; } \\
\text { Selleckchem, BGJ-398, BBI608, cisplatin, } \\
\text { paclitaxel. }\end{array}$ & $\begin{array}{l}\text { Epithelial cells } \\
\text { mesenchymal } \\
\text { derivatives }\end{array}$ & $\begin{array}{l}\text { growth factor } \\
\text { reduced BME } \\
\text { type } 2\end{array}$ & NR & [26] \\
\hline & $\begin{array}{l}\text { Endometrial epithelial } \\
\text { cells }\end{array}$ & $\begin{array}{l}\text { Establishment: ExM: Advanced } \\
\text { DMEM/F12, N2, B27 minus vitamin A, } \\
\text { Primocin, N-Acetyl-L-cysteine, } \\
\text { L-glutamine, Recombinant human EGF, } \\
\text { Recombinant human Noggin, } \\
\text { Recombinant human Rspondin-1, } \\
\text { Recombinant human FGF-10, } \\
\text { Recombinant human HGF, } \\
\text { ALK-4, -5, -7 } \\
\text { inhibitor A83-01, Nicotinamide } \\
\text { Differentiation: } \beta \text {-oestradiol, } \\
\text { progesterone, cAMP, prolactin, human }\end{array}$ & $\begin{array}{l}\text { secretory }\left(\mathrm{PAEP}^{+}\right) \text {cells } \\
\text { ciliated (acetylated-a- } \\
\left.\text { tubulin }{ }^{+}\right) \text {cells }\end{array}$ & Matrigel & $100 \%$ & [3] \\
\hline
\end{tabular}


Table 2 Summary of sources and culture conditions used in the development of various reproductive organoids (Continued)

\begin{tabular}{|c|c|c|c|c|c|c|}
\hline Organoids & Source & Culture conditions & Cell types in organoids & Matrix & $\begin{array}{l}\text { Generation } \\
\text { efficiency }\end{array}$ & Reference \\
\hline & & $\begin{array}{l}\text { chorionic gonadotropin, human } \\
\text { placental lactogen } \\
\text { Hormonal stimulation: } \beta \text {-oestradiol, } \\
\text { progesterone, cAMP }\end{array}$ & & & & \\
\hline & $\begin{array}{l}\text { Endometriotic epithelial } \\
\text { cells (ECT-O) } \\
\text { Epithelial cell from } \\
\text { hyperplastic endometrium } \\
\text { (HYP-O) }\end{array}$ & $\begin{array}{l}\text { Establishment; SOM; DMEM/F12+ } \\
\text { L-glutamine and Hepes, RSPO1- } \\
\text { conditioned medium, Noggin, B27, N2, } \\
\text { Glutamax, Insulin Transferrin Selenium, } \\
\text { Nicotinamide, A83-01, N-acetyl } \\
\text { L-cysteine, EGF, bFGF, FGF-10, } \\
\text { SB202190 (p38i) }\end{array}$ & $\begin{array}{l}\text { secretory cells } \\
\text { ciliated cells }\end{array}$ & Matrigel & $\begin{array}{l}\text { ECT-O; } \\
60 \% \\
\text { HYP-O; } \\
70 \%\end{array}$ & [24] \\
\hline & $\begin{array}{l}\text { Epithelial cell from } \\
\text { endometrial cancer }\end{array}$ & $\begin{array}{l}\text { Establishment; SOM; DMEM/F12 + L- } \\
\text { glutamine and Hepes, } \\
\text { RSPO1-conditioned medium, Noggin, } \\
\text { B27, N2, Glutamax, Insulin Transferrin } \\
\text { Selenium, Nicotinamide, A83-01, } \\
\text { N-acetyl L-cysteine, EGF, bFGF, FGF-10, } \\
\text { insulin-like growth factor } 1 \text { (IGF1), } \\
\text { hepatocyte growth factor (HGF) and } \\
\text { lipids } \\
\text { Test components: } \\
\text { paclitaxel, 5-fluorouracil, carboplatin, } \\
\text { doxorubicin and everolimus }\end{array}$ & $N R$ & Matrigel & EC-O; 40\%; & [24] \\
\hline \multirow[t]{2}{*}{ Trophoblast } & $\begin{array}{l}\text { villous cytotrophoblasts } \\
\text { (vCTBs), purified from } \\
\text { pooled first-trimester } \\
\text { placental tissues }\end{array}$ & $\begin{array}{l}\text { Establishment: basic trophoblast } \\
\text { organoid medium (b-TOM): advanced } \\
\text { DMEM/F12, HEPES, B27, N2, glutamine, } \\
\text { R-spondin, A83-01, rhEGF, rmHGF, } \\
\text { prostaglandin E2, CHIR99021, Noggin, } \\
\text { EGF, R-spondin, CHIR99021, A83-01 } \\
\text { Differentiation: } \\
\text { lacking R-spondin and CHIR99021, } \\
\text { inhibitor of Wnt response-1 (IWR-1) }\end{array}$ & $\begin{array}{l}\text { cytotrophoblasts (CTB) } \\
\text { syncytiotrophoblasts (STB) } \\
\text { extravillous trophoblast (EVT) }\end{array}$ & Matrigel & $100 \%$ & [5] \\
\hline & $\begin{array}{l}\text { trophoblast-enriched } \\
\text { cell suspensions }\end{array}$ & $\begin{array}{l}\text { Establishment: } \\
\text { basal trophoblast organoid medium } \\
\text { (TOM): EGF, FGF2, CHIR99021, A83-01, } \\
\text { R-spondin 1, HGF, PGE2, Y-27632, } \\
\text { nicotinamideDifferentiation: } \\
\text { EVT differentiation medium (EVTM): } \\
\text { advanced DMEM/ F12, } \\
\text { 2-mercaptoethanol, BSA, ITS-X, NRG1, } \\
\text { A83-01, KSR. } \\
\text { Typically after days 7-10, the medium } \\
\text { was changed to EVTM without NRG1 } \\
\text { for a further 7-10 days. }\end{array}$ & $\begin{array}{l}\text { syncytiotrophoblast (SCT) } \\
\text { villous cytotrophoblast (VCT) } \\
\text { HLA-G extravillous } \\
\text { trophoblast cells (EVT) } \\
\text { cells }\end{array}$ & Matrigel & $91 \%$ & [27] \\
\hline $\begin{array}{l}\text { Cervical } \\
\text { organoid }\end{array}$ & $\begin{array}{l}\text { cervical clear cell } \\
\text { carcinoma cells }\end{array}$ & $\begin{array}{l}\text { Establishment: } \\
\text { DMEM/F12, human EGF, R-spondin1, } \\
\text { Noggin, Y27632, Jagged-1, I-glutamine } \\
\text { Test components: } \\
\text { paclitaxel, cisplatin, gemcitabine } \\
\text { hydrochloride, crizotinib, and SU11274 }\end{array}$ & $\begin{array}{l}\text { Atypical } \\
\text { cells with clear cytoplasm } \\
\text { concordant with } \\
\text { morphological features } \\
\text { of the original tumor }\end{array}$ & Matrigel & & [28] \\
\hline
\end{tabular}

Abbreviations: A.83-01 Selective inhibitor of ALK4,5,7, EGF Epidermal growth factor, FGF Fibroblast growth factor, HGF Hepatocyte growth factor, NRG1 Neuregulin-1, Rho-KI Rho kinase inhibitor, RSPO1 R-spondin-1, NR Not-reported

and third trimester trophoblast cells, respectively [48]. However, some of these cells do not meet the criteria for human trophoblast cells as proposed by Lee et al., and do not express some important protein markers (GATA3, KRT7, and TFAPC2), the human leukocyte antigen (HLA) class I profile, the chromosome 19 miRNA cluster (C19MC), and hypomethylation of the ELF5 promoter [49]. Alternative models, such as bone morphogenetic protein 4 (BMP4)-treated human embryonic stem cells (hESCs), have also been established. Although these trophoblast-like cells are used as models for understanding early trophoblast lineage segregation, their global gene expression profiles, trophoblast-specific markers, and HLA status considerably differ from primary trophoblast populations [50].

Recently, two independent research groups developed organoid platforms for culturing first-trimester CTBs in vitro. Turco et al. reported some growth cell clusters of first-trimester placenta were seeded into Matrigel drops and grown in a basal trophoblast organoid medium (TOM) composed of EGF, FGF2, CHIR99021, A83-01, and RSPO1 (Table 1, Fig. 1). Addition of growth factors 
hepatocyte growth factor (HGF), PGE2, and Y-27632 increased cell viability and growth. In combination with TOM, the researchers observed rapid expansion of cells within a week (Fig. 2) [27]. Haider et al. showed that when villous CTB (vCTBs) were embedded in Matrigel that contained a defined cocktail of growth factors and signaling inhibitors, small cell clusters formed within several days of culture. These clusters rapidly grew and developed into organoids with irregular structures after 2-3 weeks [5]. Under these two well-defined conditions, organoid structures appeared and homogeneous trophoblast organoids were established within 10-14 days (two passages). To confirm the fetal origin of trophoblast organoids, they used microsatellite analysis and HLA typing. The generated trophoblast organoids were genetically stable after consecutive passages for more than 6 months and had mitochondrial function after cryopreservation. Finally, they provided evidence that the organoids were of clonal origin and that large organoids were formed from single cells within 3-4 weeks [5]. Identities of these trophoblast organoids were verified against trophoblast-specific criteria at similar or higher levels than the choriocarcinoma lines JEG-3 and JAR [27]. Principal component (PC) analysis of placental villi, trophoblast organoids, placental stromal cells, and decidual organoids based on 12,673 probes showed that the trophoblast organoid clusters were more closely related to the placenta with enrichment for trophoblast-specific genes such as CGB3, GATA3, and PSG6 [27]. The trophoblast organoid structures closely recapitulated the organization of placental villi in vivo, including the presence of a surrounding basement membrane beneath the VCT, SCT in the center of the organoids, syncytial masses which line the central cavity, abundant secretory organelles, and surface microvilli (confirmed by electron microscopy) [27]. The secretory function of trophoblast organoids was confirmed using proteomic analysis of the conditioned medium by liquid chromatography-tandem mass spectrometry (LC-MS/MS). Trophoblast organoids secrete a wide range of placental-specific peptides, hormones and enzymes, including pregnancy-specific glycoprotein (PSG), early placental insulin-like protein (INSL4 or EPIL), human chorionic gonadotropin (hCG), growth differentiation factor 15 (GDF15), kisspeptin (KISS1), chorionic somatomammotropin hormone 1 (CSH1), and aldose reductase [27]. HLA-G, a potent tolerogenic molecule at the maternal-fetal interface, is highly expressed by both endovascular and interstitial

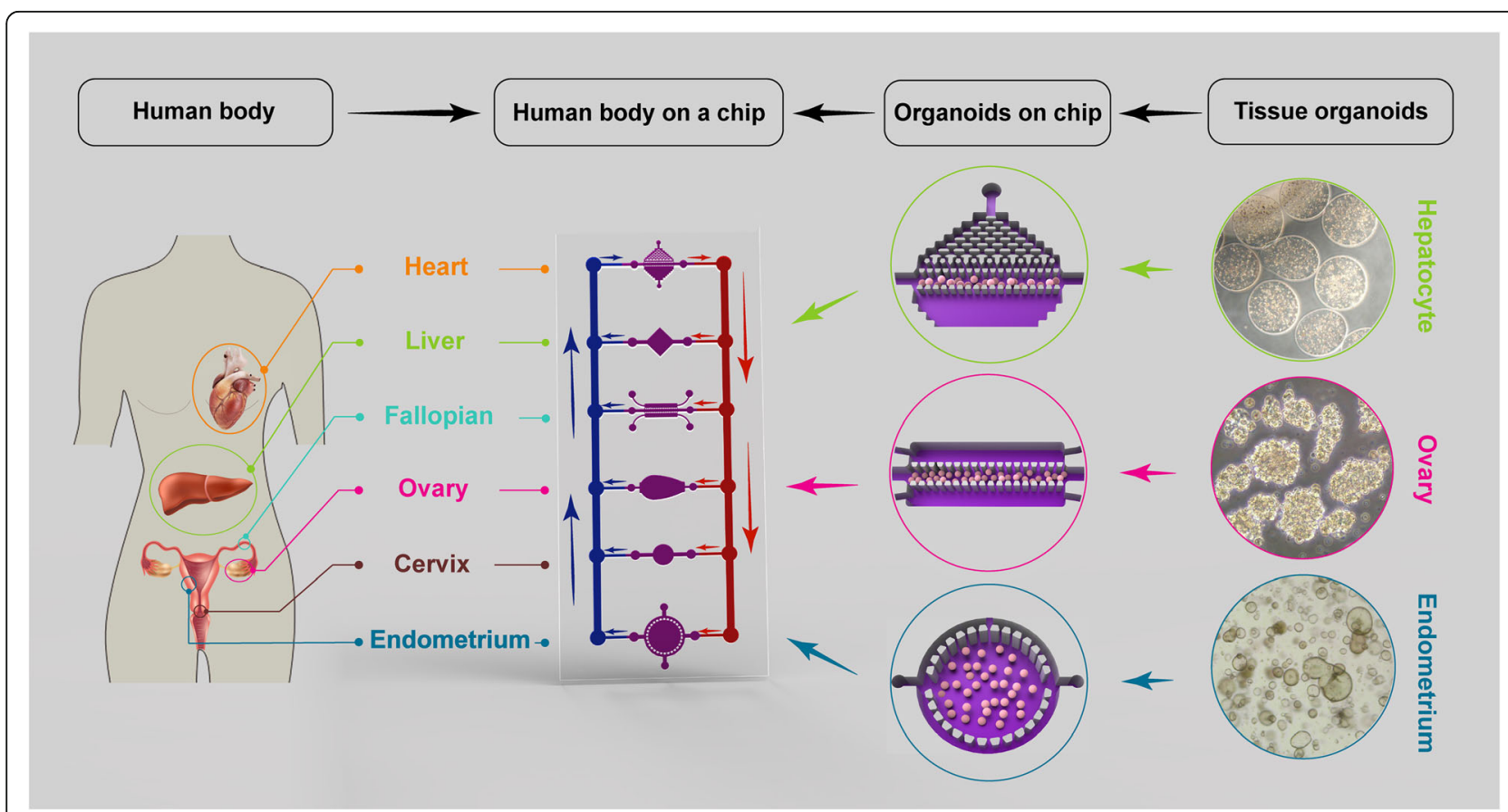

Fig. 2 The multi-organoid-on-a-chip system containing the female reproductive, the liver and the heart organoids. Culture medium can be circulated within each organoids, between organoids, and within the entire system, enabling the controlled and biomimetic distribution of biomolecules, such as metabolites and hormones. In the multi-organoid-on-a-chip systems, the responses of one organoid to drugs or toxins affect the responses of other organoids, which occurs in actual human physiology. In addition, these micro-physiological systems can use to study the effects of reproductive hormones throughout the body. The phase contrast images of organoids in the right part of figure is from correspond author's lab (un-published data). Heart image in female body has been adapted from Freepik.com designed by Kjpargeter; Liver and uterus images in female body have been adapted from Freepik.com designed by macrovector (These three elements have been adapted from resources of Freepik.com in 27 may 2020). Other elements in the figure have been designed by authors 
EVT and increases during trophoblast migration towards the spiral arteries [51]. In basic organoid medium, a few HLA $-\mathrm{G}^{+}$cells were found in trophoblast organoids, but under an EVT differentiation protocol suggested by Okae et al. [52] and by using EVT differentiation medium (EVTM). HLA-G ${ }^{+}$cells that migrated out of the organoids appeared and invaded in the 3D culture, and adhered to the plastic dish. Hence, the organoids mimicked the villous placenta in an anatomic, functional, metabolic, and endocrinologic manner [5, 27].

Cumulatively, it is suggested that the trophoblast organoid model is a promising tool to study human placental development and investigate trophoblast dysfunction and insufficiency. Developing an advanced culture system that contains both endometrial and trophoblast organoids would allow researchers to study the mechanisms that underlie maternal-fetal interactions during pregnancy.

\section{Female reproductive organoid applications Drug discovery and toxicology study}

The discovery and development of a new drug is a complex, time-consuming, and costly process accompanied by a high rate of failure [53]. Despite substantial progress made in pharmaceutical research in recent years, only a single drug among thousands of laboratory tested compounds reach the marketplace [54]. The main reason for this high rate of failure is related to the lack of reliable disease and relevant human models, and inaccurate results from animal models [55-57]. The developmental and reproductive toxicity of a vast majority of about 75 , 000-85,000 chemical substances in commerce has not been investigated [1]. Despite public concerns regarding the reproductive toxicity of chemicals, the field of reproductive toxicology (repro-toxicology) is in its infancy; therefore, more well-targeted research in this field is needed to better understand and prevent reproductive health risks. New approaches in medicine (precision medicine) focus on individual variations that lead to different patient responses for the same drug [58].

Although animal models are frequently used for drug screening and toxicity studies [59], they are not suitable. There is a need to confirm drug safety in both male and female humans [60] along with high-throughput screening of a wide range of drugs and compounds for different purposes, including development of novel contraceptive agents and vaccines, drug screening for infectious diseases, cancer drug development, gestational drug development and reproductive toxicity testing of drugs and compounds $[61,62]$. Although traditional in vitro models such as the 2D monolayer cell culture provide valuable tools for drug screening and toxicity testing and have the potential to identify drug candidates, many challenges still remain. One of the main challenges is the change in cellular responses in these model systems that contributes to their unnatural microenvironment [63]. Conventional models, including animal models and traditional culture systems, are unable to provide a platform for precision medicine. Limitations associated with these models have encouraged development and validation of new in vitro models that mimic the complex and dynamic biological features of human tissues, re-create the function and structure of these tissues, and recapitulate in vivo physiology. In this regard, organoids are 3D miniaturizations of human tissues that exhibit native tissue architecture [64] that carries out person-specific genomic and epigenetic information. Organoids provide several unique advantages for drug screening and toxicology studies. These structures are frequently derived from primary cells. They consist of multiple cell populations, possess stable genotypes, and their capacity for self-renewal facilitates their propagation and expansion for drug screening and toxicity studies [65-67]. Since the use of organoids in reproductive medicine for toxicology studies, drug development and personalized medicine is still a naïve field, more studies are required to evaluate their potential as model systems.

An impressive proof-of-concept has been reported for organoid technology for drug testing in cystic fibrosis (CF) $[68,69]$. CF is a life-shortening disease caused by loss of function mutations in the $\mathrm{CF}$ transmembrane conductance regulator $(C F T R)$ gene, which results in an accumulation of abnormally viscous, sticky mucus in the gastrointestinal and respiratory tracts [70]. Females with CF have reduced fertility due to abnormally thick, dense cervical mucus, altered ion and fluid transport throughout the reproductive tract, and endocrine abnormalities or menstrual irregularities [70]. Over the past decade, high-throughput screening has led to the identification of small molecules that restore the defective protein and ameliorate the trafficking defects (correctors) and/or augment its activity (potentiators). However, CFTR-restoring pharmacotherapy has varying degrees of efficacy in treating $\mathrm{CF}$, which suggests a contribution by more factors beyond the genetic background among individuals. Dekkers et al. have introduced a novel functional CFTR assay that used organoid cultures from rectal biopsies. They showed that forskolin induced swelling in the healthy organoids. Although this effect was strongly reduced in organoids established from CF patients, it was reversed by treatment with CFTR-restoring compounds [69]. Results of follow-up studies showed that in vitro drug responses in biopsyderived organoids positively correlated with the clinical response to therapy $[68,71]$. Hence, this platform could be used for preclinical selection of responders to pre-existent CFTR modulators as well as for the identification of novel CFTR-restoring compounds. Furthermore, in a recent study, endometrial cancer organoids exhibited patientspecific drug responses. A specific endometrial cancer 
organoid line was most sensitive to everolimus (an inhibitor of mammalian target of rapamycin [mTOR]), which suggested a strong dependence on the PI3K-AKT pathway and was in line with mutations in the pathway's signaling mediators (PTEN, PIK3CA, AKT1) [24]. These evidences have shown that organoids are amenable to toxicology studies, drug development, and personalized medicine.

\section{Organoid applications in studying reproductive infectious diseases}

There are three types of human reproductive tract infections (RTIs) - STDs such as chlamydia, gonorrhea, syphilis, genital herpes, and human immunodeficiency virus (HIV); endogenous infections, which result from overgrowth of organisms normally present in a healthy women's genital tract; and iatrogenic infections, which are associated with medical procedures such as induced abortions, poor delivery practices or intrauterine device (IUD) insertions [72, 73]. RTIs, generally seen as a 'silent' epidemic, are associated with complications of gynecologic and reproductive health, including endometritis, infertility, ectopic pregnancy, PID, chronic pelvic pain, miscarriage, and neonatal blindness. STIs/RTIs also increase the risk of HIV infection and can cause death [74-76]. The morbidity associated with RTIs affects economic productivity and the quality of life of many individuals and, ultimately, entire communities. Inaccessibility of the internal organs for analysis of the long-term consequences of acute and chronic consequences of RTIs/STDs infections in vivo have encouraged the use of many experimental models such as in vitro, ex vivo, and animal models to study pathogenesis mechanisms, discover biomarkers, and perform drug candidate screenings [77-80]. Classically, because of the limited life span of primary cell cultures, the majority of studies have been conducted in immortalized cell lines, including HEC-1A cells [9], transformed endometrial line HEC-1B [81-83], Ishikawa cell line [83], uterine epithelial cell (UECs) line ECC-1 [84], OE-E6/E7 (OEC line) [85, 86], the transformed epithelial cervical line HeLa [87], and HEp-2 epithelial cell line [88, 89]. These cell lines are relatively easy to maintain and have provided important insights into understanding host-pathogen interactions. However, the lack of complexity of these cell types, failure to recapitulate the architecture of in vivo tissues, and inability to produce some tissue-specific factors are main limitations for their use. Thus far, several 3D cell culture systems of human reproductive tissues have been developed that have the potential for use in infectious disease research. These 3D cell culture systems include the rotating wall vessel (RWV) bioreactor [90-92], organoids [3, 4, 23, 25], and organ-on-achip (OOAC) [21] models. A major challenge in infectious disease modeling is the recreation of a $3 \mathrm{D}$ microenvironment of native tissues to more accurately model the initiation and progression of an infection. Long et al. [93] and Nickerson et al. [94] have reported the first studies that investigated viral and bacterial infections in 3D models, respectively. In recent years, 3D models have gained increasing interest in the field of infectious disease because of their potential to enhance understanding of disease pathogenesis and in drug screening.

Since organoids exhibit enhanced in vivo-like features, including apico-basal polarization, appropriate localization of cell adhesion molecules, cytokine production, responses to antimicrobials and microbial products, support of commensals, and/or susceptibility to infection, they are theoretically well-suited for infectious disease studies. Various pathogens that have been studied using organoids include Helicobacter pylori (stomach organoids) [95, 96], Salmonella enterica [97] and Clostridium difficile [98] in intestinal organoids, and Zika virus (ZIKV) in human neurospheres and brain organoids [99]. Kessler et al. used human fallopian tube organoids and genital Chlamydia trachomatis (C. trachomatis) serovars $\mathrm{D}, \mathrm{K}$, and $\mathrm{E}$ for long-term in vitro infection analysis and investigated its effect on epithelial homeostasis [100]. The epithelial organoids responded to the infection with a fast, dynamic extrusion of intact Ctr inclusions and/ or infected cells into the lumen, and with compensatory cellular proliferation that demonstrated a role for epithelial cells in the defense against this pathogen. Furthermore, the acute infection led to activation of multiple paracrine growth factors (TGF- $\beta 1$, EGF, FGF). LIF signaling is a key player in the maintenance of stemness in the organoids. The gradual decrease in the number of ciliated cells and increase in CD24 + Epcam + and CD133 + cells suggests a sustained shift in the regulation of epithelial renewal during an infection. Infected organoids have a less differentiated phenotype with higher stemness potential. Moreover, their methylation data support a potential role for chronic $C$. trachomatis infection as an epigenetic modulator. $C$. trachomatis increases hypermethylation of DNA, which is an indicator of accelerated molecular aging [100]. This organoid approach could contribute to a better understanding of the long-term effects of C. trachomatis infections in the development of tubal pathologies, including the initiation of high-grade serous ovarian cancer.

Along with other infectious models, organoids also have limitations; the site of infection in most pathogens is the apical portion of the epithelium and delivery of the pathogen to the lumen of the cystic organoids is a challenge. To circumvent this limitation, microinjections have been used to deliver pathogens to the luminal side of the organoids.

\section{Organoid platform for studying reproductive cancers}

Organoid technology provided a research platform to study reproductive cancers, including ovarian and uterine cancers. Ovarian cancer is the deadliest gynecologic cancer worldwide with approximately a $35 \%$ five-year survival rate [101]. It is reported that epithelial ovarian 
cancer (EOC) accounts for $85-90 \%$ of ovarian cancers and high-grade serous carcinoma (HGSC) represents nearly $70 \%$ of all EOCs, which is associated with a poorer prognosis [101]. The majority of HGSCs appear to arise from the secretory cells of the FTE rather than from the ovarian surface epithelium [102, 103]. A better understanding of the HGSC biology, FTE transformation, and initiation and progression of HGSC using relevant in vitro human models can lead to new-targeted therapies and immunotherapeutic approaches. Recently, an iPSC- and patient-derived human FTE organoid in vitro model with the relevant cell types (ciliated and secretory) of the human fallopian tube and luminal architecture that closely mimic the tissue-specific structure has been established [22, 25]. iPSC-derived organoids can help to understand physiological and pathological processes of fallopian tubes, provide a powerful platform for drug screening, and develop novel therapies. This in vitro model can provide an appropriate model to explore the fallopian tube origin of HGSC, investigate early processes in the initiation and progression of HGSC, and study germline mutations and genetic alterations involved in HGSC [25]. While iPSC-derived FTE organoids exhibit many features of in vivo tissue, their application in highthroughput screening remains difficult due to limited culture scalability. Over the past decade, numerous literatures in the field of ovarian cancer support an oncogenic role of Notch signaling in HGSC. Notch signaling may be involved in ovarian cancer initiation, progression, metastasis, resistance to chemotherapy, cancer stem cell activity, angiogenesis, and epithelial-to-mesenchymal transition (EMT) [104]. Kessler et al. have reported that Notch signaling is a crucial regulator of differentiation and stemness in fallopian tube organoids; inhibition of the Notch pathway by addition of DBZ (Notch $\gamma$ secretase inhibitor) changes the differentiation pattern and structure of these organoids. Their results showed that 78 of the 274 'stem cell signature genes' were also significantly downregulated in the DBZ-treated organoids. This fallopian tube organoid along with the above findings enabled researchers to better understand tubal epithelium pathology, including its role in ovarian cancer because most models of tubal carcinogenesis postulate that secretory cell outgrowth is the initial step toward malignant transformation $[25,105,106]$. Potential therapeutic targeting of the molecular aberrations and cellular signaling pathways involved in initiation and progression of ovarian cancer using organoid technology may provide novel treatment options for cancer patients [104]. The ability to efficiently introduce specific genetic alterations to epithelial precursor cells or human iPSCs and generate genetically engineered organoids using the CRISPR/Cas9 system will enable researchers to gain further insight in cancer research.
Uterine malignancies represent the most common diagnosed gynecologic malignancy worldwide and the fourth most common malignancy in women [107]. About 95\% of these malignancies are endometrial carcinomas, the origin of which belongs to the endometrial glandular epithelium. The mesenchymal component such as endometrial stromal sarcoma or mixed epithelial and stromal tumors comprise the remainder [108]. The common treatment strategy for endometrial cancers includes surgery (hysterectomy with bilateral salpingooophorectomy) followed by chemotherapy and sometimes radiation therapy. If fertility is desired, hormonal therapy may be administered. However, in two metaanalyses that reviewed trials of recurrent or advanced endometrial cancer and trials on progestin in the adjuvant setting, found no evidence of substantial benefits from these drugs $[109,110]$. During the past decade, our knowledge of the genetic basis for endometrial cancers has increased exponentially. Data from the Cancer Genome Atlas (TCGA) project showed that 373 patients with endometrial carcinomas had frequent mutations in PTEN, CTNNB1, PIK3CA, ARID1A, PPP2R1A, KRAS, MYC, ERBB2, CTNNB1, CCNE1, FGFR3,S OX17, TP53, PTEN, ARID5B, PIK3R1, FBXW7, and POLE [111]. Today, treatment of endometrial cancers is not based on patients' genetic characteristics because of differences in mutations between patients. Therefore, personalized medicine that integrates data from whole genome sequencing (WGS) and whole exome sequencing (WES) to identify patients with specific cancer-related mutations with the drug screening patient-derived organoid (PDO) models can provide a platform for developing an effective therapeutic strategy for cancer patients. Successful treatment of endometrial carcinoma will require individualization of therapies based on the molecular and/or genetic make-up of the endometrial carcinoma cells. PDO cultures hold promise as an in vitro model for accurate recapitulation of a wide variety of normal and oncogenic in vivo cellular behaviors. To date, 3D organoids have been generated from biopsies and/or surgical resections of cancers of the colon [112], pancreas [113], lung [114], and prostate [115]. After the establishment of human endometrium organoid culture protocols, Turco et al. [3], Girda et al. [26], Pauli et al. [116], Dasari et al. [117], and Boretto et al. [24] have reported that it is feasible to grow organoids from primary endometrial cancer.

Organoids derived from endometrial cancer patients recapitulate the morphology of the primary tumors and show similar immunohistochemistry (IHC) characteristics with the primary tumors. IHC for MUC1 and SOX17 on both tumor and normal organoids has confirmed their glandular origin $[3,26]$. The effects of verteporfin (VP), an FDA approved light-activated drug used in photodynamic therapy (PDT) for macular degeneration, was tested on an 
organoid model generated from tumor cells of type 1 endometrial carcinoma patient tissue [117]. VP-treated organoids had less expression of YAP and phospho-YAP, and higher expression of cleaved caspase-3. This finding suggested that VP induces apoptosis and more inactive YAP in the cells of organoids [117]. A high throughput drug screen that used a comprehensive library of up-todate targeted agents was performed on uterine carcinosarcoma and endometrial adenocarcinoma organoids derived from patients with similar driver mutations in PIK3CA and PTEN. The results showed an association between genotype and drug response profiles. For the endometrial adenocarcinoma organoids, combined treatment with buparlisib (PI3K inhibitor) and olaparib (PARP inhibitor) was optimal when compared with other combination strategies. In contrast, for the endometrial adenocarcinoma organoid, the combination of buparlisib and vorinostat (HDAC inhibitor) was among the most effective treatments [116]. Results of a recent study of organoids from endometrial diseases indicated that the organoids were created from different grades and progression stages of endometrial cancer with lower efficiency compared to other endometrial conditions $(20 \%$ for endometrial cancer organoids versus $100 \%$ for eutopic endometrial organoids and $70 \%$ for hyperplastic endometrial [HYP-O] organoids). An optimized culture condition by reducing the $\mathrm{p} 38 \mathrm{i}$ concentration and adding insulin-like growth factor 1 (IGF1), HGF, and lipids enhanced the efficiency of organoids generated from endometrial cancers. Endometrial cancer organoids have morphological heterogeneity. Those derived from low-grade/stage cancers exhibit glandular-like morphology with a defined lumen. However, endometrial cancer organoids derived from high-grade/stage cancers commonly appear to be dense and lack a visible lumen [24]. Microsatellite instability (MSI) involved in the pathogenesis of about $30 \%$ of endometrial cancer cases [118] was also observed in the endometrial cancer organoids [24]. CGH array or low-coverage WGS revealed that the large majority of no somatic copy number alteration (SCNA) in primary tumors were retained in the corresponding cancer organoids, and the majority of the genetic alterations in the primary tumors were retained in the organoids after long-term expansion. Interestingly, a considerable number of new substitutions were retrieved in cancer organoids after longterm expansion [24]. Endometrial cancer organoids recapitulated the disease phenotype in vivo. Subcutaneously injected cancer organoids generated a cell mass that recapitulated histological and molecular features of the primary tumor. Orthotopic engraftment of highgrade cancer organoids into the uterine horn generated a large, invasive, and highly proliferative mass that had the potential for peritoneal metastasis [24]. These endometrial cancer organoids offer researchers a way to probe cellular pathways involved in tumorigenesis and provide a unique alternative model for endocrine profile studies, drug sensitivity, and for correlating data with the genetic landscape of individual tumors prior to treatment in humans. Clinical studies are needed to correlate organoid assay results with patient outcomes.

Organoids have been generated from young women with cervical clear cell carcinoma (cCCC), an extremely rare subtype of cervical cancer. The optimized protocol for organoid generation from gynecological tumors was applied to produce cCCC organoids. cCCC organoids were expanded in the laboratory setting by a modified Matrigel bilayer organoid culture. These organoids were successfully cryopreserved and recovered after thawing. A few mutations were identified in $\mathrm{CCCC}$ organoids and CCC component following genomic analysis. Two of these mutations were detected both in $\mathrm{CCCC}$ organoids and CCC component. Moreover, development of a xenograft was confirmed following cCCC organoid transplantation into nude mice. Spheroids derived from cCCC organoids showed drug sensitivity and proliferative capacity upon exposure to the anti-cancer drugs commonly used for gynecological cancer (paclitaxel, cisplatin, and gemcitabine) [28].

However, additional studies are needed to clearly emphasize genomic heterogeneity and transcriptome patterns between organoids and their tumors of origin before replacing the exciting models with organoids, implement cancer-derived organoids for high-throughput preclinical screenings, and design targeted and personalized therapies.

\section{Organoids to study gynecological diseases}

Endometriosis is a gynecological disorder that affects $10-15 \%$ of women worldwide and $30-50 \%$ of women with infertility. The disease is characterized by the growth of ectopic endometrial tissue outside the uterus [119]. Recently, the organoids from endometriosis patients in various disease stages (I, II, III, and IV) from both eutopic and ectopic origins have been developed [24]. These organoids displayed genomic stability during long-term expansion in culture and showed the same hormonal receptor expression as the original tissue. Endometriosis organoids injected into the peritoneal cavity generated implants that expressed endometriosis markers [24]. However, the decreased efficiency of organoid generation from endometriosis samples compared to healthy endometrial biopsies is a challenge. Moreover, the ability of endometriosis organoids to respond to hormones has yet to be addressed.

Future therapeutic applications of endometrial organoids Patients with Asherman's syndrome (AS), intrauterine adhesions (IUA), thin dysfunctional endometrium, genital 
tuberculosis, repeated implantation failure (RIF), and endometrial atrophy (EA) resistant to hormonal treatment are candidates for endometrial reconstruction [120]. AS is an uncommon gynecological disorder associated with infertility, amenorrhea, hypomenorrhea, recurrent pregnancy loss, and abnormal placentation [121]. The current therapeutic approaches for AS are limited to surgical restoration and hormonal therapy [122] Surgical complications, serious side effects of hormonal therapy, and poor pregnancy outcomes in untreated AS cases indicate the need for new, safe, and effective treatment options [123, 124]. Stem cell therapy is a possible solution that offers a promising AS and EA treatment with the ultimate goal of replenishing the cellular compartments of the endometrium [121, 124, 125]. The successful use of stem cells to improve endometrial function and structure has been reported by several studies [126-129]. For successful stem cell therapy, transplanted cells must undergo several critical steps -proliferation, differentiation to tissue specific cell types, migration, distribution into an accurate location, and integration into the target tissue. In this process, a large number of stem cells may be eliminated from the chain of distribution, leaving only a few that survive and remain active. Expansion of stem cells without differentiation and genetic alteration is one of the main limitations of stem cell therapy [130]. The true value of a cultured cell as a candidate for cell-based therapy depends on its fidelity and expansion capacity, as well as its ability to maintain a normal genetic and epigenetic status [131]. Another obstacle is the lack of control over transplanted cells.

With the emergence of organoid technology, there is an increasing interest in the use of organoids for regenerative medicine. Advantages of organoids include their ability to be created from a small biopsy sample, massive expansion in vitro, and genetic and phenotypic stability over a long-term culture $[3,25]$. Organoids have the potential to differentiate to a complete set of cell types of native tissue and provide high amounts of specific cell types for transplantation. This potential of organoids makes them different from traditional stem cell therapy, which uses specific stem/progenitor cells $[3,4,25]$. The successful engraftment of organoids has been previously reported. Results from an initial study of organoid transplantation reported that colon epithelial organoids were successfully engrafted in acute murine colitis model and covered the injured area shortly after transplantation. After a few weeks, this area contained proliferating cells and all colon specific cell-types. Transplanted organoids contributed to the normal epithelium for more than 6 months [132]. Upon transplantation, organoids have an intrinsic ability for self-renewal and self-organization, and can integrate into host tissue. Thus, stem cells or progenitor cells in organoids that have a higher survival rate and functional connections with the surrounding tissue in the host open a new and promising window for regenerative medicine [133]. Engraftment of endometrial organoids established from endometrium of TdTomato reporter mice under the kidney capsule of ovariectomized immunodeficient NOD/SCID/IL2Rgamma ${ }^{\text {null }}$ (NSG) mice [4] led to the generation of an organized structure with glandular-type protuberances [4]. Engrafted TdTomato ${ }^{+}$ endometrial organoids survived in vivo after 6 weeks, expanded, and assembled into organized glandular-type structures in response to E2 and Prog treatment [4].

Taken together, these studies show that transplanted organoids have the ability to integrate into host tissue, maintain their self-renewal and self-organizing ability, and differentiate to functional tissue-specific cells. Although organoid technology is currently in its infancy, organoids provide a promising platform for harnessing stem cell for regenerative medicine and healing damaged epithelia of specific diseases. The successful engraftment of endometrial organoids and their ability to survive in vivo and differentiate to endometrial specific cells suggests that endometrial organoid transplantation could be a novel approach to treat disorders related to an inadequate endometrium. In addition, autologous transplantation can overcome the traditional hazards associated with allogeneic transplantation.

\section{Reproductive system-on-a-chip (repro-on-a-chip): balancing sex differences in preclinical research}

In the past decades, several studies have demonstrated that efficacy and safety of drug treatments are sexspecific and the female sex tends to have a higher risk of developing adverse drug reactions (ADRs) compared with the male sex $[134,135]$. The reproductive system is comprised of sex organs that work together and produce various factors and hormones. These factors are not only necessary for reproduction and regulation of gamete production, but they also affect various organs and tissues, including the cardiovascular system, immune system, gastrointestinal system, nervous system, and liver [136]. Reproductive hormones and factors underlie sexbased differences in disease pathogenesis and development, and alter pharmacokinetics and responses to therapeutic agents [136]. One of the molecular mechanisms responsible for sex differences in drug metabolism may be due to differences in hepatic gene expression, especially those regulated by sex hormones (such as CYP3A4) [137]. CYP3A4, the major human drug-metabolizing cytochrome P450 (CYP) is expressed at higher levels in females [138]. Many drugs that are substrates of CYP3A4 such as cyclosporine, erythromycin, and nifedipine have a higher rate of clearance in females than males [137]. In the liver, sexual dimorphism in hepatic gene expression such as P450s is regulated by the plasma growth hormone $(\mathrm{GH})$ that is synthesized by the pituitary gland [137]. The GH release pattern is 
pulsatile in males and almost continuous in females [139]. Reproductive steroid hormones can modulate GH action by regulating $\mathrm{GH}$ secretion from the pituitary glands and peripherally modulate $\mathrm{GH}$ signaling pathways through the GH receptor (GHR) [140]. In addition, a proteomic analysis on total liver protein extracts from male and female rats has demonstrated that liver protein expression is more affected by gender than by nutritional status [141]. There is a paucity of data on sex differences in preclinical and biomedical research and drug development. Traditional in vitro systems such as a monolayer culture of cell lines or primary cells without considering their sex poorly recapitulate human tissues and lead to inaccuracies in preclinical data and inefficiencies in drug discovery [136]. This is an important biological limitation because tissues and organs that work together in the body communicate and impact each other's function. Therefore, in order to sufficiently model the human body for biomedical and pharmaceutical researches, a clear need exists for in vitro models that recapitulate the reproductive system and incorporate its endocrine signaling to the other organs of the body. In this regard, OOAC and human-on-a-chip microfluidic technology devices have recently garnered great attention and offer an alternative platform for animal models to test the efficacy and toxicity of new drugs on several cell types, tissues, and organs within a more biologically relevant environment $[21,142]$. This technology is a promising platform to model human diseases and study tissue development in vitro and may significantly affect the future of medicine. Currently, our view of the OOAC and human-on-a-chip is like a jigsaw puzzle with different connecting pieces. However, the pieces will gradually connect and, in the near future, this complicated puzzle will be completed [21, 142].

The reproductive system-on-a-chip (repro-on-a-chip) is promising model to overcome these gaps and provide a new platform that incorporates reproductive sex hormones in preclinical research to address sexual dimorphism in biological processes, disease development, and improve sex-specific drug development [21]. By developing the male and female repro-on-a-chip, an important piece will be added to the human-on-a-chip puzzle, and will raise the hope to provide a suitable in vitro model to study reproductive development, fertility, and reproductive disorders such as implantation disorders or even cancers. In addition, these micro-physiological systems can allow researchers to study the effects of reproductive hormones throughout the body. Moreover, an available dynamic flow microenvironment in the OOAC platform mimics chemophysical signaling between different tissues and provides a controlled microfluidic environment for pharmacokinetic modeling and toxicology studies. This approach is useful for fundamental studies in reproductive biology such as oocyte maturation and modeling pathological conditions of infertility, endometriosis, STD, premature ovarian failure, and polycystic ovary syndrome [143]. Recently, Xiao et al. have integrated female reproductive organs, including the ovaries, fallopian tubes, uterus, and cervix with peripheral organs, including the liver, into a microfluidic system called EVATAR. This EVATAR phenocopies the in vivo female reproductive tract and the hormone profile of the female 28-day menstrual cycle by linking tissues with a sustained circulating flow. Advantages of this technology are the use of human samples (except ovaries that are obtained from rats), long-term culture, and communication between different tissues in a microfluidic platform [21]. However, tissue explants are not expandable and this is a serious challenge for producing scalable chips. The use of female reproductive organoids would allow researchers to fabricate highly scalable and low-cost microfluidic devices for highthroughput assays.

Recent advances in organoid culture systems, including fallopian tubes, endometrium, testicular, and prostate organoids hold promise for the combination of male and female reproductive organoids with other technologies, such as microfluidics technology (Fig. 2). This combined technology would create a multi-organoid-on-a-chip platform and provide human-on-a-chip for clinical applications, drug discoveries, and toxicology studies. In the multi-organoid-on-a-chip systems, the responses of one organoid to drugs or toxins impact the responses of other organoids, which occurs in actual human physiology. These organoids offer insights into the mechanisms of action of drugs or toxins that cannot be predicted by single-organ models. The combination of primary or stem cell-derived human reproductive organoids with other organoids on-a-chip would provide an emerging in vitro platform to study sex-specific differences and the mechanisms of male and female physiology and pathophysiology. This would provide high-value interpretable data to enable the development of more effective and safer drugs, and sex-based therapeutic strategies for precision medicine.

\section{Challenges and future perspectives}

The current version of reproductive organoids faces some challenges; one limitation in the current organoid culture protocols is the requirement of animal-derived and chemically undefined extracellular matrices such as Matrigel. This could limit high-throughput screens and hinder direct transplantation because of medical legislation. Furthermore, tissues display highly anisotropic, heterogeneous, and nonlinear physical properties that depend on their composition, architecture, and pathology [144]. However, isotropic Matrigel is unable to recapitulate the in vivo dynamic changes. To address these issues, hybrid polyethylene glycol (PEG) hydrogels that can change their biophysical and biochemical properties on demand may serve as next-generation designer matrices for organoid production [145]. The lack of stroma, 
blood vessels, innervation, and immune cells could be a hindrance to organoid research. Development of intestinal organoids with a functional enteric nervous system [146], human pancreatic cancer organoids with matched stromal and immune cells [147], and human prostate organoid co-cultured with prostate stromal cells [148] are good examples of the development of more complex organoid-based structures. Tackling these challenges will open new avenues for biomedical research. Other innovations, such as the use of a bioreactor and optimizing media composition, may minimize variation in culture conditions. Providing a scaffold of biomaterials along with combining microfluidics and organoid technologies may improve tissue architecture. Recent advances in CRISPR/Cas9 and gene editing technologies [149], and single-cell RNA-seq technologies [150] as well as 3D live-cell imaging using light sheet microscopy [151] will greatly accelerate applicability of organoids in biomedical research.

\section{Conclusion}

Despite current limitations, organoids provide an exciting era as in vitro models of the reproductive system that allow for reproductive biology research, accurate modeling of reproductive organs, clinical decision-making, and individualized medicine for patients with gynecologic cancers and diseases such as endometriosis. In addition, biobanked organoids can be used for drug screening or in vitro trials to predict individual patient drug responses. Advances on cutting-edge technologies will doubtless improve this novel tool for clinical application.

\section{Abbreviations}

STD: Sexually transmitted disease; ECM: Extracellular matrix; PID: Pelvic inflammatory disease; ALI: Air-liquid interphase; OEC: Oviductal epithelia cells; EGF: Epidermal growth factor; FGF: Fibroblast growth factor; FTE: Fallopian tube epithelium; CGH: Comparative genomic hybridization; CTB: Cytotrophoblast; EVT: Extravillous; STB: Syncytiotrophoblast; HLA: Human leukocyte antigen; C19MC: Chromosome 19 miRNA cluster; BMP4: Bone morphogenetic protein 4; HESC: Human embryonic stem cell; VCTB: Villous CTB; PC: Principal component; LC-MS/MS: Liquid chromatography-tandem mass spectrometry; PSG: Pregnancy-specific glycoprotein; EPIL: Early placental insulin-like; HCG: Human chorionic gonadotropin; GDF15: Growth differentiation factor 15; KISS1: Kisspeptin; CSH1: Chorionic somatomammotropin hormone 1; EVTM: EVT differentiation medium; CF: Cystic fibrosis; CFTR: CF transmembrane conductance regulator; MTOR: Mammalian target of rapamycin; RTI: Reproductive tract infection; HIV: Human immunodeficiency virus; IUD: Intrauterine device; UEC: Uterine epithelial cell; RWV: Rotating wall vessel; OOAC: Organ-on-a-chip; ZIKV: Zika virus; EOC: Epithelial ovarian cancer; HGSC: High-grade serous carcinoma; EMT: Epithelial-tomesenchymal transition; TCGA: The cancer genome atlas; WGS: Whole genome sequencing; WES: Whole exome sequencing; PDO: Patientderived organoid; IHC: Immunohistochemistry; VP: Verteporfin; PDT: Photodynamic therapy; MSI: Microsatellite instability; SCNA: Somatic copy number alteration; cCCC: Cervical clear cell carcinoma; AS: Asherman's syndrome; IUA: Intrauterine adhesions; RIF: Repeated implantation failure; EA: Endometrial atrophy; ADR: Adverse drug reactions; CYP: Cytochrome P450; GH: Growth hormone; GHR: GH receptor; PEG: Polyethylene glycol

\section{Acknowledgements}

We would like to express our appreciation to our colleagues at Royan Institute for their helpful discussions. This article was extracted from a thesis written by Mr. Heidar Heidari Khoei in the School of Medicine, Shahid Beheshti University of Medical Sciences (registration no. 343).

\section{Authors' contributions}

All the authors researched data for this article, substantially contributed to the discussion of the content, wrote, reviewed, and/or edited it before submission. The authors read and approved the final manuscript.

\section{Funding}

This work was supported by grants from the National Institute for Medical Research Development (NIMAD, grant no. 987770) and Royan Institute (grant no. 96000189) to H.B., and Shahid Beheshti University of Medical Sciences (grant no. 12466) and the Iran National Science Foundation (INSF, grant no. 96004094) to A.P.

\section{Availability of data and materials}

All data supporting the conclusion of this article are included in this published article.

Ethics approval and consent to participate

Not applicable.

\section{Consent for publication}

Not applicable.

\section{Competing interests}

The authors declare that they have no competing interests.

\section{Author details}

${ }^{1}$ Department of Stem Cells and Developmental Biology, Cell Science Research Center, Royan Institute for Stem Cell Biology and Technology, ACECR, P.O. Box: 16635-148, Tehran 1665659911, Iran. '2Urogenital Stem Cell Research Center, Shahid Beheshti University of Medical Sciences, Tehran, Iran. ${ }^{3}$ Department of Biology and Anatomical Sciences, School of Medicine, Shahid Beheshti University of Medical Sciences, P.O. Box: 19395-4719, Tehran, Iran. ${ }^{4}$ Department of Developmental Biology, University of Science and Culture, Tehran, Iran.

Received: 29 February 2020 Accepted: 11 June 2020 Published online: 18 June 2020

\section{References}

1. Young AN, Moyle-Heyrman G, Kim JJ, Burdette JE. Microphysiologic systems in female reproductive biology. Exp Biol Med. 2017;242(17):1690-700.

2. Laronda MM, Burdette JE, Kim JJ, Woodruff TK. Recreating the female reproductive tract in vitro using iPSC technology in a linked microfluidics environment. Stem Cell Res Ther. 2013;4(1):S13.

3. Turco MY, Gardner L, Hughes J, Cindrova-Davies T, Gomez MJ, Farrell L, et al. Long-term, hormone-responsive organoid cultures of human endometrium in a chemically defined medium. Nat Cell Biol. 2017;19(5): 568-77.

4. Boretto M, Cox B, Noben M, Hendriks N, Fassbender A, Roose H, et al. Development of organoids from mouse and human endometrium showing endometrial epithelium physiology and long-term expandability. Development. 2017;144(10):1775-86.

5. Haider S, Meinhardt G, Saleh L, Kunihs V, Gamperl M, Kaindl U, et al. Selfrenewing trophoblast organoids recapitulate the developmental program of the early human placenta. Stem cell Rep. 2018;11(2):537-51.

6. Weimar CH, Uiterweer EDP, Teklenburg G, Heijnen CJ, Macklon NS. In-vitro model systems for the study of human embryo-endometrium interactions. Reprod Biomed Online. 2013;27(5):461-76.

7. Truskey GA. Human microphysiological systems and organoids as in vitro models for toxicological studies. Front Public Health. 2018;6:185.

8. Ferraz MA, Henning HH, Stout TA, Vos PL, Gadella BM. Designing 3dimensional in vitro oviduct culture systems to study mammalian fertilization and embryo production. Ann Biomed Eng. 2017;45(7):1731-44.

9. Łaniewski P, Gomez A, Hire G, So M, Herbst-Kralovetz MM. Human threedimensional endometrial epithelial cell model to study host interactions 
with vaginal bacteria and Neisseria gonorrhoeae. Infect Immun. 2017;85(3): e01049-16.

10. Yin X, Mead BE, Safaee H, Langer R, Karp JM, Levy O. Engineering stem cell organoids. Cell Stem Cell. 2016;18(1):25-38.

11. Bersinger NA, Genewein E, Müller O, Altermatt H, McKinnon B, Mueller M. Morphology of human endometrial explants and secretion of stromal marker proteins in short-and long-term cultures. Gynecol Surg. 2010;7(1):75-80.

12. Schäfer WR, Fischer $L$, Roth $K$, Jüllig AK, Stuckenschneider JE, Schwartz $P$, et al. Critical evaluation of human endometrial explants as an ex vivo model system: a molecular approach. Mol Hum Reprod. 2010;17(4):255-65.

13. Lancaster MA, Knoblich JA. Organogenesis in a dish: modeling development and disease using organoid technologies. Science. 2014; 345(6194):1247125

14. Hill SJ, Decker B, Roberts EA, Horowitz NS, Muto MG, Worley MJ, et al. Prediction of DNA repair inhibitor response in short-term patient-derived ovarian cancer organoids. Cancer Discov. 2018;8(11):1404-21.

15. Kopper O, de Witte CJ, Lõhmussaar K, Valle-Inclan JE, Hami N, Kester L, et al. An organoid platform for ovarian cancer captures intra-and interpatient heterogeneity. Nat Med. 2019;25(5):838.

16. Maenhoudt N, Defraye C, Boretto M, Jan Z, Heremans R, Boeckx B, et al. Developing organoids from ovarian cancer as experimental and preclinica models. Stem Cell Rep. 2020;14(4):717-29.

17. Maru Y, Tanaka N, Itami M, Hippo Y. Efficient use of patient-derived organoids as a preclinical model for gynecologic tumors. Gynecol Oncol. 2019;154(1):189-98.

18. Brüssow KP, Ratky J, Rodriguez-Martinez H. Fertilization and early embryonic development in the porcine fallopian tube. Reprod Domest Anim. 2008;43: 245-51.

19. Salvador S, Gilks B, Köbel M, Huntsman D, Rosen B, Miller D. The fallopian tube: primary site of most pelvic high-grade serous carcinomas. Int J Gynecol Cancer. 2009;19(1):58-64.

20. Price M, Ades A, Welton N, Simms I, Horner P. Pelvic inflammatory disease and salpingitis: incidence of primary and repeat episodes in England. Epidemiol Infect. 2017;145(1):208-15.

21. Xiao S, Coppeta JR, Rogers HB, Isenberg BC, Zhu J, Olalekan SA, et al. A microfluidic culture model of the human reproductive tract and 28-day menstrual cycle. Nat Commun. 2017;8:14584.

22. Yucer N, Holzapfel M, Vogel TJ, Lenaeus L, Ornelas L, Laury A, et al. Directed differentiation of human induced pluripotent stem cells into fallopian tube epithelium. Sci Rep. 2017;7(1):10741

23. Xie Y, Park E-S, Xiang D, Li Z. Long-term organoid culture reveals enrichment of organoid-forming epithelial cells in the fimbrial portion of mouse fallopian tube. Stem Cell Res. 2018;32:51-60

24. Boretto M, Maenhoudt N, Luo X, Hennes A, Boeckx B, Bui B, et al. Patient-derived organoids from endometrial disease capture clinical heterogeneity and are amenable to drug screening. Nat Cell Biol. 2019; 21(8):1041-51.

25. Kessler M, Hoffmann K, Brinkmann V, Thieck O, Jackisch S, Toelle B, et al. The notch and Wnt pathways regulate stemness and differentiation in human fallopian tube organoids. Nat Commun. 2015;6:8989.

26. Girda E, Huang EC, Leiserowitz GS, Smith LH. The use of endometrial cancer patient-derived organoid culture for drug sensitivity testing is feasible. Int J Gynecol Cancer. 2017;27(8):1701-7.

27. Turco MY, Gardner L, Kay RG, Hamilton RS, Prater M, Hollinshead MS, et al. Trophoblast organoids as a model for maternal-fetal interactions during human placentation. Nature. 2018;564(7735):263.

28. Maru Y, Tanaka N, Ebisawa K, Odaka A, Sugiyama T, Itami M, et al. Establishment and characterization of patient-derived organoids from a young patient with cervical clear cell carcinoma. Cancer Sci. 2019; 110(9):2992.

29. de Faria A, Zancanela D, Ramos A, Torqueti M, Ciancaglini P. Estrogen and phenol red free medium for osteoblast culture: study of the mineralization ability. Cytotechnology. 2016;68(4):1623-32.

30. Liu X, Chen B, Chen L, Ren W-T, Liu J, Wang G, et al. U-shape suppressive effect of phenol red on the epileptiform burst activity via activation of estrogen receptors in primary hippocampal culture. PLoS One. 2013;8(4):e60189.

31. Kim S-M, Kim J-S. A review of mechanisms of implantation. Develop Reprod. 2017;21(4):351

32. Morice $P$, Leary A, Creutzberg C, Abu-Rustum N, Darai E. Endometrial cancer. Lancet. 2016;387(10023):1094-108.
33. Bläuer M, Heinonen $\mathrm{P}$, Martikainen $\mathrm{P}$, Tomas $\mathrm{E}$, Ylikomi T. A novel organotypic culture model for normal human endometrium: regulation of epithelial cell proliferation by estradiol and medroxyprogesterone acetate. Hum Reprod. 2005;20(4):864-71.

34. Senol S, Sayar I, Ceyran AB, Ibiloglu I, Akalin I, Firat U, et al. Stromal clues in endometrial carcinoma: loss of expression of $\beta$-catenin, epithelialmesenchymal transition regulators, and estrogen-progesterone receptor. Int J Gynecol Pathol. 2016;35(3):238.

35. Pineda MJ, Lu Z, Cao D, Kim JJ. Influence of cancer-associated endometrial stromal cells on hormone-driven endometrial tumor growth. Horm Cancer. 2015:6(4):131-41.

36. Arnold JT, Kaufman DG, Seppala M, Lessey BA. Endometrial stromal cells regulate epithelial cell growth in vitro: a new co-culture model. Hum Reprod. 2001;16(5):836-45.

37. Stzepourginski I, Nigro G, Jacob J-M, Dulauroy S, Sansonetti PJ, Eberl G, et al CD34+ mesenchymal cells are a major component of the intestinal stem cells niche at homeostasis and after injury. Proc Natl Acad Sci. 2017;114(4): E506-E13.

38. Wang $Y$, Di Salvo M, Gunasekara DB, Dutton J, Proctor A, Lebhar MS, et al. Self-renewing monolayer of primary colonic or rectal epithelial cells. Cell Mol Gastroenterol Hepatol. 2017;4(1):165-82.e7.

39. He N, van Iperen $L$, de Jong D, Szuhai $K$, Helmerhorst FM, van der Westerlaken LA, et al. Human extravillous trophoblasts penetrate decidual veins and lymphatics before remodeling spiral arteries during early pregnancy. PLoS One. 2017;12(1):e0169849.

40. Knöfler M, Haider S, Saleh L, Pollheimer J, Gamage TK, James J. Human placenta and trophoblast development: key molecular mechanisms and model systems. Cell Mol Life Sci. 2019;76(18):3479-96.

41. Chang C-W, Wakeland AK, Parast MM. Trophoblast lineage specification, differentiation and their regulation by oxygen tension. J Endocrinol. 2018; 236(1):R43-56

42. Krishna U, Bhalerao S. Placental insufficiency and fetal growth restriction. J Obstet Gynaecol India. 2011;61(5):505-11.

43. Gagnon R. Placental insufficiency and its consequences. Eur J Obstet Gynecol Reprod Biol. 2003;110:S99-S107.

44. Burton GJ, Jauniaux E. What is the placenta? Am J Obstet Gynecol. 2015; 213(4):S6 e1-S6. e4.

45. Grigsby PL. Animal models to study placental development and function throughout normal and dysfunctional human pregnancy. Semin Reprod Med. 2016;34(1):11-6.

46. Malassine A, Frendo JL, Evain-Brion D. A comparison of placental development and endocrine functions between the human and mouse model. Hum Reprod Update. 2003;9(6):531-9.

47. Orendi K, Kivity V, Sammar M, Grimpel Y, Gonen R, Meiri H, et al. Placental and trophoblastic in vitro models to study preventive and therapeutic agents for preeclampsia. Placenta. 2011;32:S49-54.

48. Weber M, Knoefler I, Schleussner E, Markert UR, Fitzgerald JS. HTR8/SVneo cells display trophoblast progenitor cell-like characteristics indicative of selfrenewal, repopulation activity, and expression of "Stemness-" associated transcription factors. Biomed Res Int. 2013;2013:243649.

49. Lee CQ, Gardner L, Turco M, Zhao N, Murray MJ, Coleman N, et al. What is trophoblast? A combination of criteria define human first-trimester trophoblast. Stem Cell Rep. 2016;6(2):257-72.

50. Telugu B, Adachi K, Schlitt J, Ezashi T, Schust D, Roberts R, et al. Comparison of extravillous trophoblast cells derived from human embryonic stem cells and from first trimester human placentas. Placenta. 2013;34(7):536-43.

51. McMaster MT, Librach CL, Zhou Y, Lim K-H, Janatpour MJ, DeMars R, et al. Human placental HLA-G expression is restricted to differentiated cytotrophoblasts. J Immunol. 1995;154(8):3771-8.

52. Okae H, Toh H, Sato T, Hiura H, Takahashi $\mathrm{S}$, Shirane $K$, et al. Derivation of human trophoblast stem cells. Cell Stem Cell. 2018;22(1):50-63.e6.

53. Biyani M, Nishigaki K, Biyani M. Chapter 20 - biomolecular display technology: a new tool for drug discovery. In: Verma AS, Singh A, editors. Animal biotechnology. San Diego: Academic; 2014. p. 369-84.

54. Taylor D. The pharmaceutical industry and the future of drug development. In: Pharmaceuticals in the Environment: the Royal Society of Chemistry; 2016. p. 1-33.

55. Mak IW, Evaniew N, Ghert M. Lost in translation: animal models and clinical trials in cancer treatment. Am J Transl Res. 2014;6(2):114.

56. Henderson VC, Kimmelman J, Fergusson D, Grimshaw JM, Hackam DG. Threats to validity in the design and conduct of preclinical efficacy studies: 
a systematic review of guidelines for in vivo animal experiments. PLoS Med. 2013;10(7):e1001489.

57. Horvath P, Aulner N, Bickle M, Davies AM, Del Nery E, Ebner D, et al. Screening out irrelevant cell-based models of disease. Nat Rev Drug Discov. 2016;15(11):751-69.

58. Dolsten M, Søgaard M. Precision medicine: an approach to R\&D for delivering superior medicines to patients. Clin Transl Sci. 2012;1 (1):7.

59. Zuberi A, Lutz C. Mouse models for drug discovery. Can new tools and technology improve translational power? ILAR J. 2017;57(2):178-85.

60. Soldin OP, Mattison DR. Sex differences in pharmacokinetics and pharmacodynamics. Clin Pharmacokinet. 2009;48(3):143-57.

61. Brannen KC, Chapin RE, Jacobs AC, Green ML. Alternative models of developmental and reproductive toxicity in pharmaceutical risk assessment and the 3Rs. ILAR J. 2017;57(2):144-56.

62. Chapman KL, Holzgrefe H, Black LE, Brown M, Chellman G, Copeman C, et al. Pharmaceutical toxicology: designing studies to reduce animal use, while maximizing human translation. Regul Toxicol Pharmacol. 2013;66(1):88-103.

63. Edmondson R, Broglie JJ, Adcock AF, Yang L. Three-dimensional cell culture systems and their applications in drug discovery and cell-based biosensors. Assay Drug Dev Technol. 2014;12(4):207-18.

64. Clevers H. Modeling development and disease with organoids. Cell. 2016; 165(7):1586-97.

65. Augustyniak J, Bertero A, Coccini T, Baderna D, Buzanska L, Caloni F. Organoids are promising tools for species-specific in vitro toxicological studies. J Appl Toxicol. 2019;39(12):1610-22.

66. Liu F, Huang J, Ning B, Liu Z, Chen S, Zhao W. Drug discovery via humanderived stem cell organoids. Front Pharmacol. 2016;7:334.

67. Fang Y, Eglen RM. Three-dimensional cell cultures in drug discovery and development. SLAS Discov. 2017;22(5):456-72.

68. Dekkers JF, Berkers G, Kruisselbrink E, Vonk A, De Jonge HR, Janssens HM, et al. Characterizing responses to CFTR-modulating drugs using rectal organoids derived from subjects with cystic fibrosis. Sci Transl Med. 2016; 8(344):344ra84.

69. Dekkers JF, van der Ent CK, Beekman JM. Novel opportunities for CFTRtargeting drug development using organoids. Rare Dis. 2013;1 (1):939-45.

70. Kreda SM, Davis CW, Rose MC. CFTR, mucins, and mucus obstruction in cystic fibrosis. Cold Spring Harb Perspect Med. 2012;2(9):a009589.

71. Noordhoek J, Gulmans V, Van Der Ent K, Beekman JM. Intestinal organoids and personalized medicine in cystic fibrosis: a successful patient-oriented research collaboration. Curr Opin Pulm Med. 2016;22(6):610-6.

72. Rabiu KA, Adewunmi AA, Akinlusi FM, Akinola Ol. Female reproductive tract infections: understandings and care seeking behaviour among women of reproductive age in Lagos, Nigeria. BMC Womens Health. 2010;10(1):8.

73. Wasserheit JN, Holmes KK. Reproductive tract infections: challenges for international health policy, programs, and research. In: Germain A, Holmes KK, Piot P, Wasserheit JN, editors. Reproductive tract infections: global impact and priorities for Women's reproductive health. Boston: Springer US; 1992. p. 7-33.

74. Hillier SL, Nugent RP, Eschenbach DA, Krohn MA, Gibbs RS, Martin DH, et al. Association between bacterial vaginosis and preterm delivery of a low-birthweight infant. N Engl J Med. 1995;333(26):1737-42.

75. Taylor BD, Darville T, Haggerty CL. Does bacterial vaginosis cause pelvic inflammatory disease? Sex Transm Infect. 2013;40(2):117-22.

76. Prusty RK, Unisa S. Reproductive tract infections and treatment seeking behavior among married adolescent women $15-19$ years in India. Int J MCH AIDS. 2013;2(1):103.

77. Spurgeon ME, Uberoi A, McGregor SM, Wei T, Ward-Shaw E, Lambert PF. A novel in vivo infection model to study papillomavirus-mediated disease of the female reproductive tract. mBio. 2019;10(2):e00180-19.

78. Merbah M, Introini A, Fitzgerald W, Grivel JC, Lisco A, Vanpouille C, et al. Cervico-vaginal tissue ex vivo as a model to study early events in HIV-1 infection. Am J Reprod Immunol. 2011;65(3):268-78.

79. Hvid M, Baczynska A, Deleuran B, Fedder J, Knudsen HJ, Christiansen G, et al. Interleukin-1 is the initiator of fallopian tube destruction during chlamydia trachomatis infection. Cell Microbiol. 2007;9(12):2795-803.

80. Xue Y, Zheng H, Mai Z, Qin X, Chen W, Huang T, et al. An in vitro model of azithromycin-induced persistent chlamydia trachomatis infection. FEMS Microbiol Lett. 2017;364(14):fnx145.

81. Paul T, Knight S, Raulston J, Wyrick P. Delivery of azithromycin to chlamydia trachomatis-infected polarized human endometrial epithelial cells by polymorphonuclear leucocytes. J Antimicrob Chemother. 1997;39(5):623-30.
82. Davis C, Raulston J, Wyrick P. Protein disulfide isomerase, a component of the estrogen receptor complex, is associated with chlamydia trachomatis serovar E attached to human endometrial epithelial cells. Infect Immun. 2002;70(7):3413-8.

83. Guseva NV, Dessus-Babus SC, Whittimore JD, Moore CG, Wyrick PB. Characterization of estrogen-responsive epithelial cell lines and their infectivity by genital chlamydia trachomatis. Microbes Infect. 2005;7(15): 1469-81.

84. Mukura LR, Hickey DK, Rodriguez-Garcia M, Fahey JV, Wira CR. Chlamydia trachomatis regulates innate immune barrier integrity and mediates cytokine and antimicrobial responses in human uterine ECC-1 epithelial cells. Am J Reprod Immunol. 2017;78(6):e12764.

85. King AE, Wheelhouse N, Cameron S, McDonald SE, Lee KF, Entrican G, et al. Expression of secretory leukocyte protease inhibitor and elafin in human fallopian tube and in an in-vitro model of chlamydia trachomatis infection. Hum Reprod. 2009;24(3):679-86.

86. Shaw JLV, Wills GS, Lee K-F, Horner PJ, McClure MO, Abrahams VM, et al. Chlamydia trachomatis infection increases fallopian tube PROKR2 via TLR2 and NFKB activation resulting in a microenvironment predisposed to ectopic pregnancy. Am J Pathol. 2011;178(1):253-60.

87. Guseva NV, Dessus-Babus S, Moore CG, Whittimore JD, Wyrick PB. Differences in chlamydia trachomatis serovar $E$ growth rate in polarized endometrial and endocervical epithelial cells grown in three-dimensional culture. Infect Immun. 2007;75(2):553-64.

88. Kokab A, Jennings R, Eley A, Pacey AA, Cross NA. Analysis of modulated gene expression in a model of interferon- $\gamma$-induced persistence of chlamydia trachomatis in HEp-2 cells. Microb Pathog. 2010;49(5):217-25.

89. Huston WM, Gloeckl S, de Boer L, Beagley KW, Timms P. Apoptosis is induced in chlamydia trachomatis-infected HEp-2 cells by the addition of a combination innate immune activation compounds and the inhibitor Wedelolactone. Am J Reprod Immunol. 2011;65(5):460-5.

90. Nickerson CA, Richter EG, Ott CM. Studying host-pathogen interactions in 3-D: Organotypic models for infectious disease and drug development. J Neuroimmune Pharmacol. 2007;2(1):26-31.

91. Hjelm BE, Berta AN, Nickerson CA, Arntzen CJ, Herbst-Kralovetz MM. Development and characterization of a three-dimensional Organotypic human vaginal epithelial cell Model1. Biol Reprod. 2010;82(3):617-27.

92. LaMarca HL, Ott CM. Höner zu Bentrup K, LeBlanc CL, Pierson DL, Nelson $A B$, et al. three-dimensional growth of extravillous cytotrophoblasts promotes differentiation and invasion. Placenta. 2005;26(10):709-20.

93. Long JP, Pierson S, Hughes JH. Rhinovirus replication in HeLa cells cultured under conditions of simulated microgravity. Aviat Space Environ Med. 1998; 69(9):851-6.

94. Nickerson CA, Goodwin TJ, Terlonge J, Ott CM, Buchanan KL, Uicker WC, et al. Three-dimensional tissue assemblies: novel models for the study of salmonella enterica serovar typhimurium pathogenesis. Infect Immun. 2001; 69(11):7106-20.

95. McCracken KW, Catá EM, Crawford CM, Sinagoga KL, Schumacher M, Rockich $\mathrm{BE}$, et al. Modelling human development and disease in pluripotent stem-cell-derived gastric organoids. Nature. 2014;516(7531):400.

96. Bartfeld $\mathrm{S}, \mathrm{Clevers} \mathrm{H}$. Organoids as model for infectious diseases: culture of human and murine stomach organoids and microinjection of helicobacter pylori. J Vis Exp. 2015;105:e53359.

97. Forbester JL, Goulding D, Vallier L, Hannan N, Hale C, Pickard D, et al. The interaction of Salmonella enterica Serovar typhimurium with intestinal organoids derived from human induced pluripotent stem cells. Infect Immun. 2015;83(7):2926-34.

98. Leslie JL, Huang S, Opp JS, Nagy MS, Kobayashi M, Young VB, et al. Persistence and toxin production by Clostridium difficile within human intestinal organoids result in disruption of epithelial paracellular barrier function. Infect Immun. 2015;83(1):138-45.

99. Garcez PP, Loiola EC, da Costa RM, Higa LM, Trindade P, Delvecchio R, et al. Zika virus impairs growth in human neurospheres and brain organoids. Science. 2016;352(6287):816-8.

100. Kessler M, Hoffmann K, Fritsche K, Brinkmann V, Mollenkopf H-J, Thieck $\mathrm{O}$, et al. Chronic chlamydia infection in human organoids increases stemness and promotes age-dependent $\mathrm{CpG}$ methylation. Nat Commun. 2019;10(1):1194

101. Botesteanu D-A, Lee J-M, Levy D. Modeling the dynamics of high-grade serous ovarian cancer progression for transvaginal ultrasound-based screening and early detection. PLoS One. 2016;11(6):e0156661. 
102. Zhang W, Wei L, Li L, Yang B, Kong B, Yao G, et al. Ovarian serous carcinogenesis from tubal secretory cells. Histol Histopathol. 2015;30(11): 1295-302.

103. Kurman RJ, Shih I-M. The origin and pathogenesis of epithelial ovarian cancer-a proposed unifying theory. Am J Surg Pathol. 2010;34(3):433.

104. Groeneweg JW, Foster R, Growdon WB, Verheijen RH, Rueda BR. Notch signaling in serous ovarian cancer. J Ovarian Res. 2014;7(1):95.

105. Chen EY, Mehra K, Mehrad M, Ning G, Miron A, Mutter GL, et al. Secretory cell outgrowth, PAX2 and serous carcinogenesis in the fallopian tube. J Pathol. 2010;222(1):110-6.

106. Erickson BK, Conner MG, Landen CN. The role of the fallopian tube in the origin of ovarian cancer. Am J Obstet Gynecol. 2013;209(5):409-14.

107. Arnold M, Pandeya N, Byrnes G, Renehan AG, Stevens GA, Ezzati M, et al. Global burden of cancer attributable to high body-mass index in 2012: a population-based study. Lancet Oncol. 2015;16(1):36-46.

108. Marshall AD, Bailey CG, Champ K, Vellozzi M, O'Young P, Metierre C, et al. CTCF genetic alterations in endometrial carcinoma are pro-tumorigenic. Oncogene. 2017;36:4100.

109. Kokka F, Brockbank E, Oram D, Gallagher C, Bryant A. Hormonal therapy in advanced or recurrent endometrial cancer. Cochrane Database Syst Rev. 2010:(12):Cd007926.

110. Martin-Hirsch PP, Bryant A, Keep SL, Kitchener HC, Lilford R. Adjuvant progestagens for endometrial cancer. Cochrane Database Syst Rev. 2011;6: CD001040.

111. Zhang J, Späth SS, Marjani SL, Zhang W, Pan X. Characterization of cancer genomic heterogeneity by next-generation sequencing advances precision medicine in cancer treatment. Precis Clin Med. 2018;1(1):29-48.

112. Sato $T$, Stange $D E$, Ferrante $M$, Vries RG, Van Es JH, Van Den Brink S, et al. Long-term expansion of epithelial organoids from human colon, adenoma, adenocarcinoma, and Barrett's epithelium. Gastroenterology. 2011;141(5):1762-72.

113. Boj SF, Hwang C-I, Baker LA, Chio IIC, Engle DD, Corbo V, et al. Organoid models of human and mouse ductal pancreatic cancer. Cell. 2015;160(1): 324-38.

114. Gao B, Peyton M, Huang C, Park H, Girard L, Sorrelle N, et al. 3D spheroid/ organoid models of lung cancer to study lung cancer pathogenesis and testing of new therapeutics. J Thorac Oncol. 2017;12(8):S1544.

115. Gao D, Vela I, Sboner A, laquinta PJ, Karthaus WR, Gopalan A, et al. Organoid cultures derived from patients with advanced prostate cancer. Cell. 2014;159(1):176-87.

116. Pauli C, Hopkins BD, Prandi D, Shaw R, Fedrizzi T, Sboner A, et al. Personalized in vitro and in vivo cancer models to guide precision medicine. Cancer Discov. 2017;7(5):462-77.

117. Dasari VR, Mazack V, Feng W, Nash J, Carey DJ, Gogoi R. Verteporfin exhibits YAP-independent anti-proliferative and cytotoxic effects in endometrial cancer cells. Oncotarget. 2017;8(17):28628.

118. Kunitomi H, Banno K, Yanokura M, Takeda T, lijima M, Nakamura K, et al. New use of microsatellite instability analysis in endometrial cancer. Oncol Lett. 2017;14(3):3297-301.

119. Anglesio MS, Papadopoulos N, Ayhan A, Nazeran TM, Noë M, Horlings HM, et al. Cancer-associated mutations in endometriosis without cancer. $\mathrm{N}$ Engl J Med. 2017:376(19):1835-48.

120. Gargett CE, Ye L. Endometrial reconstruction from stem cells. Fertil Steril. 2012;98(1):11-20.

121. Cervelló I, Gil-Sanchis C, Santamaría X, Cabanillas S, Díaz A, Faus A, et al. Human CD133+ bone marrow-derived stem cells promote endometrial proliferation in a murine model of Asherman syndrome. Fertil Steril. 2015; 104(6):1552-60 e3

122. Gargett CE, Healy DL. Generating receptive endometrium in Asherman's syndrome. J Hum Reprod Sci. 2011;4(1):49.

123. Kuramoto G, Takagi S, Ishitani K, Shimizu T, Okano T, Matsui H. Preventive effect of oral mucosal epithelial cell sheets on intrauterine adhesions. Hum Reprod. 2014;30(2):406-16.

124. Singh N, Mohanty S, Seth T, Shankar M, Bhaskaran S, Dharmendra S. Autologous stem cell transplantation in refractory Asherman's syndrome: a novel cell based therapy. J Hum Reprod Sci. 2014;7(2):93.

125. Alawadhi F, Du H, Cakmak H, Taylor HS. Bone marrow-derived stem cell (BMDSC) transplantation improves fertility in a murine model of Asherman's syndrome. PLoS One. 2014;9(5):e96662.

126. Lee YJ, Yi KW. Bone marrow-derived stem cells contribute to regeneration of the endometrium. Clin Exp Reprod Med. 2018;45(4):149-53.
127. Azizi R, Aghebati-Maleki L, Nouri M, Marofi F, Negargar S, Yousefi M. Stem cell therapy in Asherman syndrome and thin endometrium: stem cell-based therapy. Biomed Pharmacother. 2018;102:333-43.

128. Domnina A, Novikova P, Obidina J, Fridlyanskaya I, Alekseenko L, Kozhukharova I, et al. Human mesenchymal stem cells in spheroids improve fertility in model animals with damaged endometrium. Stem Cell Res Ther. 2018;9(1):50.

129. Sudoma I, Pylyp L, Kremenska Y, Goncharova Y. Application of autologous adipose-derived stem cells for thin endometrium treatment in patients with failed ART programs. J Stem Cell Ther Transplant. 2019;3:001-8.

130. Bayart E, Cohen-Haguenauer O. Technological overview of iPS induction from human adult somatic cells. Curr Gene Ther. 2013;13(2):73-92.

131. Pera MF. Stem cells: the dark side of induced pluripotency. Nature. 2011; 471(7336):46-7.

132. Yui S, Nakamura T, Sato T, Nemoto $Y$, Mizutani T, Zheng $X$, et al. Functional engraftment of colon epithelium expanded in vitro from a single adult Lgr5+ stem cell. Nat Med. 2012;18(4):618-23.

133. Wei N, Quan Z, Tang H, Zhu J. Three-dimensional organoid system transplantation Technologies in Future Treatment of central nervous system diseases. Stem Cells Int. 2017;2017:5682354.

134. Soldin OP, Chung SH, Mattison DR. Sex differences in drug disposition. Biomed Res Int. 2011:2011:187103.

135. Gandhi M, Aweeka F, Greenblatt RM, Blaschke TF. Sex differences in pharmacokinetics and pharmacodynamics. Annu Rev Pharmacol Toxicol. 2004;44:499-523.

136. Eddie SL, Kim JJ, Woodruff TK, Burdette JE. Microphysiological modeling of the reproductive tract: a fertile endeavor. Exp Biol Med. 2014;239(9): $1192-202$.

137. Waxman DJ, Holloway MG. Sex differences in the expression of hepatic drug metabolizing enzymes. Mol Pharmacol. 2009;76(2):215-28.

138. Zanger UM, Schwab M. Cytochrome P450 enzymes in drug metabolism: regulation of gene expression, enzyme activities, and impact of genetic variation. Pharmacol Ther. 2013;138(1):103-41.

139. MacGregor D, Leng G. Modelling the hypothalamic control of growth hormone secretion. J Neuroendocrinol. 2005;17(12):788-803.

140. Chowen JA, Frago LM, Argente J. The regulation of GH secretion by sex steroids. Eur J Endocrinol. 2004;151(Suppl 3):U95-100.

141. Valle A, Silvestri E, Moreno M, Chambery A, Oliver J, Roca P, et al. Combined effect of gender and caloric restriction on liver proteomic expression profile. J Proteome Res. 2008:7(7):2872-81.

142. Kimura H, Sakai Y, Fujii T. Organ/body-on-a-chip based on microfluidic technology for drug discovery. Drug Metab Pharmacokinet. 2018;33(1):43-8.

143. Nawroth J, Rogal J, Weiss M, Brucker SY, Loskill P. Organ-on-a-Chip Systems for Women's health applications. Adv Healthc Mater. 2018;7(2):1700550.

144. Mouw JK, Ou G, Weaver VM. Extracellular matrix assembly: a multiscale deconstruction. Nat Rev Mol. 2014;15(12):771.

145. Gjorevski N, Sachs N, Manfrin A, Giger S, Bragina ME, Ordóñez-Morán P, et al. Designer matrices for intestinal stem cell and organoid culture. Nature. 2016;539(7630):560.

146. Workman MJ, Mahe MM, Trisno S, Poling HM, Watson CL, Sundaram N, et al Engineered human pluripotent-stem-cell-derived intestinal tissues with a functional enteric nervous system. Nat Med. 2017;23(1):49.

147. Tsai S, McOlash L, Palen K, Johnson B, Duris C, Yang Q, et al. Development of primary human pancreatic cancer organoids, matched stromal and immune cells and 3D tumor microenvironment models. BMC Cancer. 2018;18(1):335.

148. Richards Z, McCray T, Marsili J, Zenner ML, Manlucu JT, Garcia J, et al. Prostate stroma increases the viability and maintains the branching phenotype of human prostate organoids. iScience. 2019:12:304-17.

149. Singh V, Gohil N, Ramirez Garcia R, Braddick D, Fofié CK. Recent advances in CRISPR-Cas9 genome editing technology for biological and biomedical investigations. J Cell Biochem. 2018;119(1):81-94.

150. Tang $X$, Huang Y, Lei J, Luo H, Zhu X. The single-cell sequencing: new developments and medical applications. Cell Biosci. 2019;9(1):53.

151. Chatterjee K, Pratiwi FW, Wu FCM, Chen P, Chen B-C. Recent progress in light sheet microscopy for biological applications. Appl Spectrosc. 2018; 72(8):1137-69.

\section{Publisher's Note}

Springer Nature remains neutral with regard to jurisdictional claims in published maps and institutional affiliations. 